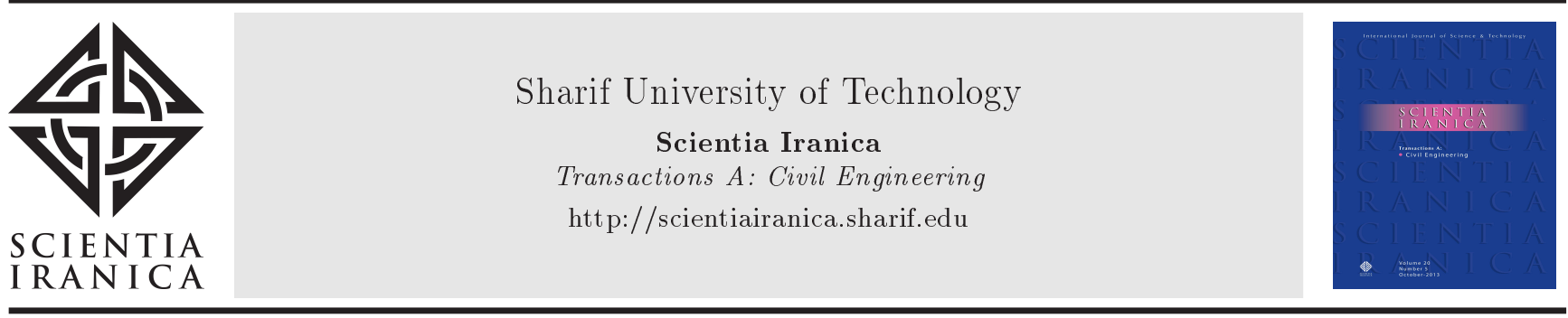

\title{
Simulation analysis of the effect of doubling and electrification on the reliability of the rail networks: A case study of Tehran-Mashhad railroad
}

\author{
M. Shakibayifar ${ }^{a, *}$, A. Sheikholeslami ${ }^{a}$, F. Corman ${ }^{b}$, and Y. Shafahi ${ }^{c}$ \\ a. Department of Transportation Engineering and Planning, School of Civil Engineering, Iran University of Science \& Technology, \\ Tehran, Iran. \\ b. Department of Marine and Transport Technology, Delft University of Technology, Mekelweg 2, 2628 CD Delft, The Netherland. \\ c. Department of Transportation Engineering and Planning, School of Civil Engineering, Sharif University of Technology, Tehran, \\ Iran.
}

Received 31 October 2016; received in revised form 25 February 2017; accepted 18 April 2017

KEYWORDS
Reliability;
Electrification;
Average delay;
Infrastructure
doubling;
Simulation modeling;
Railway.

\section{Introduction}

Railway operation planning is extremely complex, mainly because it is a decision problem under many uncertainties [1]. Several uncertain factors may eventually result in some minor or major deviations from the pre-planned timetable. Train delays depend on

\footnotetext{
Corresponding author.

E-mail addresses: m_shakibayi@civileng.iust.ac.ir ( $M$. Shakibayifar); sheikh@iust.ac.ir (A. Sheikholeslami); francesco.corman@ivt.baug.ethz.ch (F. Corman); shafahi@sharif.ir (Y. Shafahi).
}

doi: $10.24200 /$ sci.2017.4226

\begin{abstract}
The reliability assessment of railway services is a complex procedure affected by many different factors. A railway system is reliable when trains arrive at their destination within the allowed delay threshold. The objective of this study is to investigate the effect frastructure doubling and electrification on the reliability of the train schedules. In this study, the advanced event-driven stochastic simulation software was developed to determine the reliability of the train movements. The calculation of the average train delay as a benchmark was conducted to evaluate performance. Average train delay was compared with the acceptable delay to define a new benchmark to determine the reliability of train movements. In addition, the delay cascading effect was analyzed along the railway line in order to better illustrate a number of correlations between the arrival and departure delays at different stations. The model was validated through a real-world case study of the Iranian railway. Successful validation of the developed simulation system demonstrated that the model provides accurate reliability estimations in both congested and non-congested situations. Furthermore, the experimental results showed that electrification and doubling improve the reliability significantly.
\end{abstract}

(C) 2018 Sharif University of Technology. All rights reserved. the traffic volume and the capacity utilization and comprise a significant percentage of the travelling time. Furthermore, the delays cause high costs of passenger dissatisfaction and penalties for late deliveries of freight for railway companies [2]. In this situation, the management of train services is a complex procedure [3]. One of the common criteria to evaluate the quality of rail systems is the reliability of train movements [4]. Reliability is the ability of a system or component to perform its required functions under stated conditions for a specified period of time [5]. Rail transit systems seek to schedule trains in order to avoid passenger dissatisfaction and improve the service reliability [6]. The existence of single-track segments causes problems in 
overtaking and crossing of trains, which increase delays in the rail network. One practical way of improving the capacity is the process of expanding a single-track rail segment to a double-track rail called doubling. An important question is how to obtain a trade-off between capacity and reliability. Existing methods for capacity analysis can be divided into simulation, optimization, and analytical methods [7]. Mathematical optimization models have been extensively employed to measure train delays and determine the train timetables as well as the operational capacity (e.g., see [8-10]). In addition, simulation approaches seem to be an effective and promising method to appraise the trade-off between capacity and reliability [11]. The simulation technique allows the evaluation of a system prior to its creation, making it possible to compare different executable options without disrupting the actual system; finally, it is usable by many people due to its uncomplicated structure and accessibility to simulation-specified computer languages [12]. Simulation modeling has been used extensively in railway applications as a flexible and powerful approach for evaluating the robustness and reliability of trains' timetable (e.g., see [13-16]).

The present study is motivated by the situation where services' reliability is of concern. In Iranian rail network, the important causes of passenger train delays include unscheduled waiting time at overtaking stations, engine breakdown, infrastructure failure, and unplanned stops [17]. According to the archived data from the Iranian Railways, the average delay from 2005 to the end of 2009 was nearly 30 minutes for each passenger train [18]. Literature shows that the optimal investment in the rail infrastructure can improve the reliability of the system for both existing and new train services [19]. The objective of this study is to analyze the effect of doubling and electrification on the reliability of the rail networks. A stochastic eventbased simulation system is developed to determine timetable's reliability. Thus, the aim is to analyze to what extent the electrification and doubling can increase trains' movement reliability. The designed simulation system considers stochastic parameters associated with train characteristics, e.g., stochastic train running time, probabilistic dwelling time, and random failure of rail infrastructure. As a case study, a reliability analysis of Tehran-Mashhad corridor is conducted and the results are presented. In order to investigate the effect of doubling on the timetable's reliability, two cases are considered. In the first case, the railway system is partially of single and double tracks. In the second case, the whole route consists of doubletrack segments. In order to compare electrified and non-electrified railways, they are compared in the same setup. A method is proposed to make a fair comparison of these two cases.

The contributions of the present study to the research community are as follows: First, an advanced event-driven simulation system is developed to calculate the reliability of the train schedules. As will be explained in detail below, the reliability of the train services is referred to the train's total delay at destinations against allowed intervals. Second, in order to conduct a fair comparative analysis, the operational parameters of the electrified routes are modified and implemented in the non-electrified route.

\section{Literature review}

Reliability is one of the important factors in railway both for passengers and cargo. Reliability of railway transportation is a complex matter since there are many causes of conflict and at least as many causes for delays to spread around in space and time [20]. Different possible explanations of the reliability have been used in the literature. Rietveld et al. [21] defined reliability in seven different ways:

1. Punctuality, i.e., the probability that trains arrive less than $x$ minutes late;

2. The probability of an early departure;

3. The mean difference between the expected arrival time and the scheduled arrival time;

4. The mean delay of an arrival given that one arrives late;

5. The mean delay of an arrival given that one arrives more than $x$ minutes late;

6. The standard deviation of arrival times;

7. The adjusted standard deviation of the arrival times (ignoring the early arrivals), and various other more complex measures to represent the seriousness of unreliability.

Another measure of the reliability has been defined as the value of average delay divided by the value of travelling time. The "average delay" is a good measure for timetable's reliability [20]. The term reliability is used quite broadly; in this research, when a railway system is reliable, the trains run properly most of the time within the allowed delay threshold. Thus, our reliability definition is the most similar approach to the third definition of Rietveld et al. [21].

In the context of railway transportation systems, improving the service quality in an uncertain condition is a real challenge [22]. In what follows, we refer to the most relevant simulation studies determining unreliability in the rail network. Hallowell and Harker [23] developed a prediction method for the schedule reliability of a partially double-tracked rail route. A simulation model was designed for the generation of a reliable schedule. Huisman and Boucherie [24] developed a stochastic analytical model for analyzing delays at a 
double-track route. Their models were based on train frequencies and running times only, not on detailed timetables with arrival and departure times. Carey and Carville [25] focused on the improvement of the generated timetables by reducing the consequences of delay propagation in large stations by a simulation approach. Yin et al. [26] presented a simulation-based approach to measuring the transit reliability. The developed model addressed the interaction between network performance and passenger's route choice behavior.

Vromans et al. [20] developed a simulation package called SIMONE (a discrete-event simulation model) used as a simulation platform of a given timetable. In SIMONE, many complex details in railway systems, such as interactions between trains, headway times on the tracks, platform occupations, and connections for travelers, were taken into account. They developed a rule to decrease the propagation of delays and present new measures to show a strong correlation between speed differences and reliability. Furthermore, an innovative stochastic linear program was presented to evaluate and optimize timetables. Dingler et al. [27] attempted to provide a better understanding of the impacts of various aspects of train type heterogeneity to enable more effective planning and efficient rail operations. Train dispatching simulation software was used to analyze the effect of various combinations of intermodal, unit and passenger trains on a hypothetical signalized, single-track line. They also suggested certain operating strategies that may increase the capacity caused by train-type heterogeneity.

Murali et al. [28] suggested a simulation-based technique that generates delay estimates over track segments as a function of traffic conditions, as well as network topology. Marinov and Viegas [29] designed a simulation model to study and evaluate freight train operations. To capture the global impact of freight operation over the whole network, the model separated rail networks into components, such as rail lines, stations, and so on, and, then, put all these components into an interconnecting queuing system. Zheng et al. [30] presented the definition of the carrying capacity reliability of railway network. They developed a model for capacity calculation and conducted a numerical experiment with different levels of Origin-toDestination (OD) demand. The result shows that the fluctuation of OD demand directly affects the carrying capacity of railway networks.

Simulation in combination with optimization techniques can be adopted for logistic problems; e.g., see Eskandari, et al. [31], and Ilati et al. [32]. Corman et al. [33] investigated the application of an optimization-based framework to evaluate different robust timetables under stochastic disturbances. A real case was used in a Dutch railway network with heavy traffic. A trade-off was found between the train delays and the passenger travelling time. In a railway context, quantifying the relations of delays among the sequence of stations is important and supports forecasting potential train conflicts, generating robust train dispatching procedures, generating robust train timetables, and evaluating the quality of train dispatching algorithms. Shakibayifar et al. [34] proposed mathematical modeling approaches to the integrated train scheduling and infrastructure upgrading in railway networks. A mixedinteger linear programming formulation was proposed that deals with the optimum schedule of trains and the best segments for doubling. Two heuristics were proposed to reduce the complexity of the problem. The result of the proposed methodology demonstrates that it can significantly decrease the total delay of trains with the most serious emphasis on the bottleneck segments. Hassannayebi et al. [35] adopted a discrete-event object-oriented simulation model, which implements a variable neighborhood search algorithm in order to recover the system performance after disturbance. The simulation model was tested against different probabilistic disturbance scenarios. Shakibayifar et al. [36] presented a simulation-based optimization approach to rescheduling train traffic in uncertain disruptions. The train conflicts were resolved using a dynamic priority rule with the aim of minimizing the total delay time. The proposed simulation model was tested on real instances of the Iranian rail network. The outcomes specify that the optimization approach has considerable advantages, when compared to existing solution methods.

To the best of the author's knowledge, a few number of studies analyzed the effect of double-tracking and electrification on the reliability of the rail networks. The main motivation of the current study is to quantify the reliability of a railway system using a simulationbased decision support framework considering random failure and the stochastic disturbances of train operations. The next section provides the description of the problem.

The structure of the paper is organized as follows. In Section 3, the problem is described in detail. Afterward, the details of the methodology are presented in Section 4. The framework of the simulation method is presented in Sections 5. The researchers organize and interpret the results of extensive simulation experiments on a real case in Section 6, followed by conclusions in Section 7.

\section{Problem statement}

In order to describe the formulation better, the problem and the situation are first stated in which the reliability analysis is conducted. The network diagram is a single bi-directional route including both the single- 


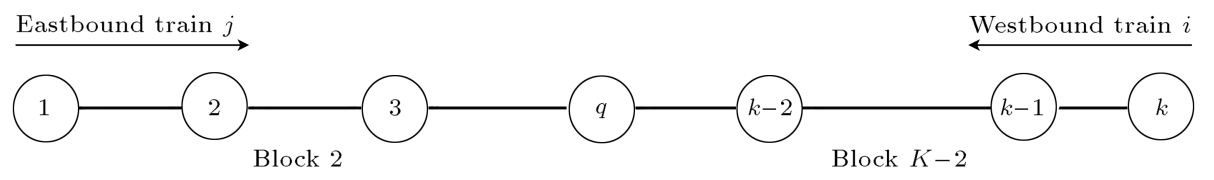

Figure 1. The network infrastructure under investigation.

Table 1. The input data of the simulation model.

\begin{tabular}{|c|c|}
\hline Category information & Details \\
\hline 1. Geometry of axis rail & Including geographical location, slope, arches, bridges, tunnels, and train speed of axes complications. \\
\hline 2. Geometry of stations & Including geographical location, the slope of the station, and the elevation above sea level. \\
\hline $\begin{array}{l}\text { 3. The non-geometric } \\
\text { properties of blocks }\end{array}$ & $\begin{array}{l}\text { The number of lines per block, maximum speed train passing through the block, wind speed, } \\
\text { time blocking blocks, and blocks maintenance time. }\end{array}$ \\
\hline $\begin{array}{l}\text { 4. The non-geometric } \\
\text { characteristics of stations }\end{array}$ & $\begin{array}{l}\text { Including the order of the stations, the number of stations and platforms including acceptance and } \\
\text { deployment and supply lines, maximum speed train passing through the station, chapel, underpass, the } \\
\text { dispatch system, the symptoms lines, type and number of needles, intersection, open or closed stations. }\end{array}$ \\
\hline $\begin{array}{l}\text { 5. The technical information } \\
\text { and specifications of locomotives }\end{array}$ & $\begin{array}{l}\text { Including train power, speed, weight of locomotives, maximum braking force, the number of axes, } \\
\text { burst speed, sticking coefficient, length, engine power for different gears, fuel consumption for different } \\
\text { ribs, introduced Davis relationship or other relationship resistance, and resistance relationship for } \\
\text { speed higher than a specified limit. }\end{array}$ \\
\hline 6. Technical information of wagons & $\begin{array}{l}\text { Including name, weight, length, effective area, the number of axes, the relationship Davis } \\
\text { (user selectable), and the type of brake. }\end{array}$ \\
\hline 7. Technical information of trains & $\begin{array}{l}\text { Train numbers, maximum train speed, and the number of instruments constituting each train } \\
\text { transporter (it should be noted that characteristics such as weight or length are considered } \\
\text { according to the type of trains' locomotives and wagons, and their number is calculated by } \\
\text { the application.), diesel or electric, to move the train. }\end{array}$ \\
\hline
\end{tabular}

and double-track segments. The corridor includes $K$ stations and $K-1$ block segments. Suppose a different set of eastbound and westbound trains (Figure 1). Each block of the route can be of a single-track or double-track segment. A double-track railway usually involves running one track in each direction, compared to a single-track railway where trains in both directions share the same track. Train crossing is possible either at stations or parts of the route with double-track railways, and overtaking is only possible at stations. A train starts from the origin according to the initial schedule and passes intermediate blocks to arrive at the destination. The aim is to analyze the effect of doubling and electrification on the train's delays. The next section describes the proposed methodology of reliability assessment.

\section{Methodology}

This study's purpose primarily concerns itself with presenting an operational and consistent simulation system to find the extent to which the reliability of the train's services can be improved which is subject to two factors: doubling and electrification. The input data of the simulation model are provided in
Table 1. The developed simulation system has some new features compared to other existing simulation methods: First, it considers most important sources of randomness in train operations, e.g., stochastic running time of trains on block sections, breakdown/failure probabilities at both rail segments and inside stations. Second, the simulation model's configuration has been customized by the inclusion of railway operations and rules existing in the Iranian railway network (e.g., the train stops for praying services). First, a detail description of the simulation model is presented. The discussion will continue to present assumptions and system explanation.

\subsection{A simulation model for reliability analysis} This section presents the simulation logic and algorithms including input and output data. By considering a set of stochastic parameters, the train's operations along the route are simulated. Thereby, an analysis of the delays that may occur in the network is possible. The presented simulation model is an event-based stochastic simulation system to analyze the reliability of the rail system.

$\mathrm{C \#}$ programming language is used in software development. The application is designed by a high- 


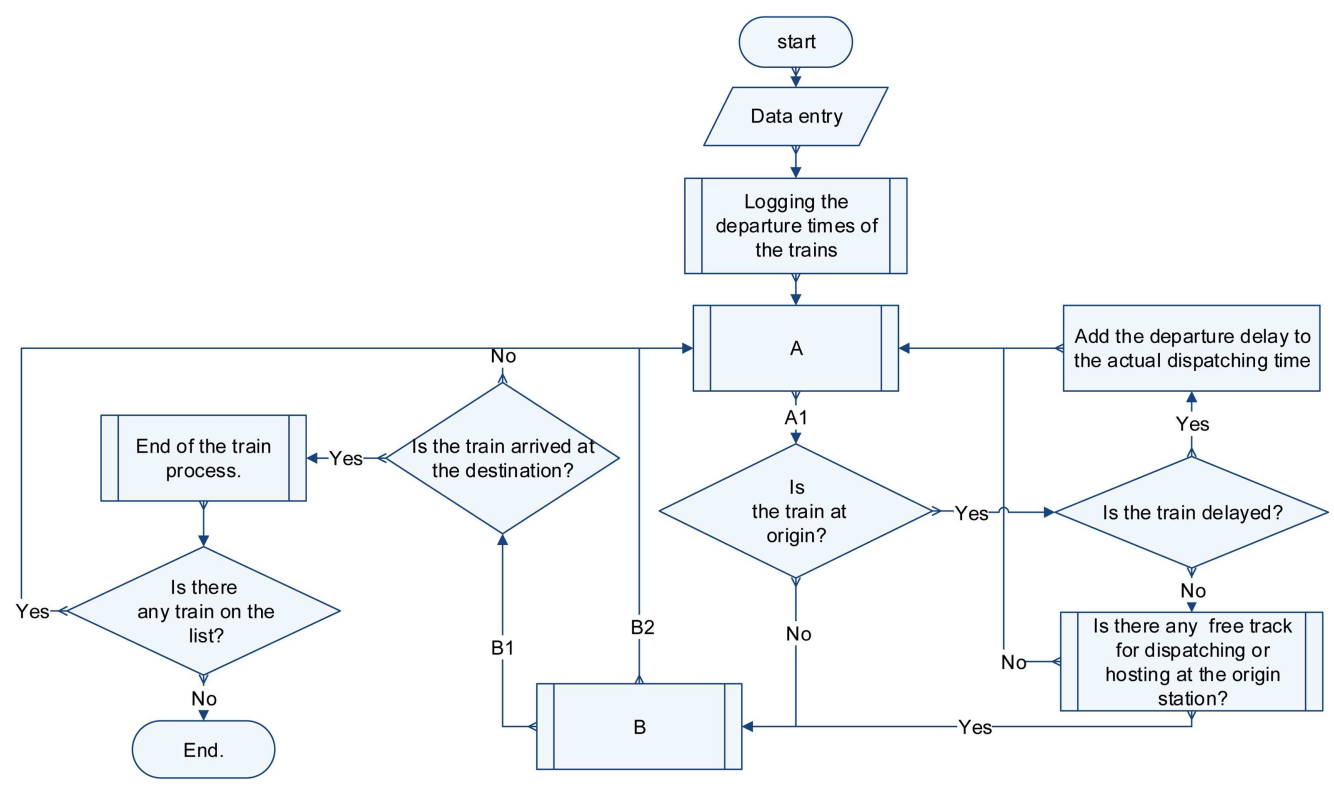

Figure 2. Diagram of the train movement simulation.

level NET Framework object-oriented language. The simulation model will be able to include input data, e.g., geometric data of blocks and stations, locomotives and wagons technical specifications, traction and resistance relationships to generate outputs such as travelling times of trains on the block and the entire route, the fuel consumption, instantaneous and average train speeds, and traction resistance moment diagram (including arc resistance, slope, tunnels, and Davis resistance).

The core of the simulation system includes a train movement control module. Figure 2 shows basics of the main steps of the proposed simulation algorithm. As seen, our simulator uses a priority rule-based eventlist in order to find a feasible timetable for trains. All unscheduled trains are sorted in ascending order of their priorities. Trains depart according to the pre-planned timetable. The train with the highest priority is dispatched first until it crosses the entire line. Subsequently, the next train from the predefined list is scheduled and so on, until all trains reach their destinations. The main routine of the dispatching algorithm is described below:

1. Set simulation clock $(t=0)$;

2. Initialize system state;

3. Prepare event list (ascending order of time);

4. Consider the first event and invoke event routine;

5. Use a look-ahead procedure that finds a new event (either stop at the current station or move to the next one);

6. Update the system states and the associated variables (train positions, current utilization, and so on);
7. Check the feasibility of the train departure;

8. Insert a new event in an appropriate time position;

9. Check whether an event list is empty;

10. Generate output reports:

- Train timetable graphs (time-station diagrams);

- Train delays at destinations.

Figure 3 shows the flow diagram of a train dispatching model. This part of the simulator controls the priority list and dispatches train in the pre-specified order. In the continued procedure, the train movement license is checked (Figure 4). The availability of the track is controlled by detecting the type of the segment (Figure 5). Likewise, the availability of a free track at the next station is checked through the procedure represented in Figure 6. The train movement control module works as follows: In the first step, the algorithm finds the next segment where the train can stop. Afterwards, the algorithm checks whether the path is free for that position or not. If the train is allowed to dispatch, it reserves a free path (a free block section and a free track at the nest stations). Afterwards, the departure time is logged and the train moves to the next segment or section. After the dwelling or the running time operation, the train releases the segment or a track of the station just when it left. The algorithm then returns to the second step, when reaching the destination station.

\subsection{Train operation modeling}

This section provides the assumptions made on the train operation during the simulation experiments. The stochastic parameters herein are train running times and random failure at stations. The first step 


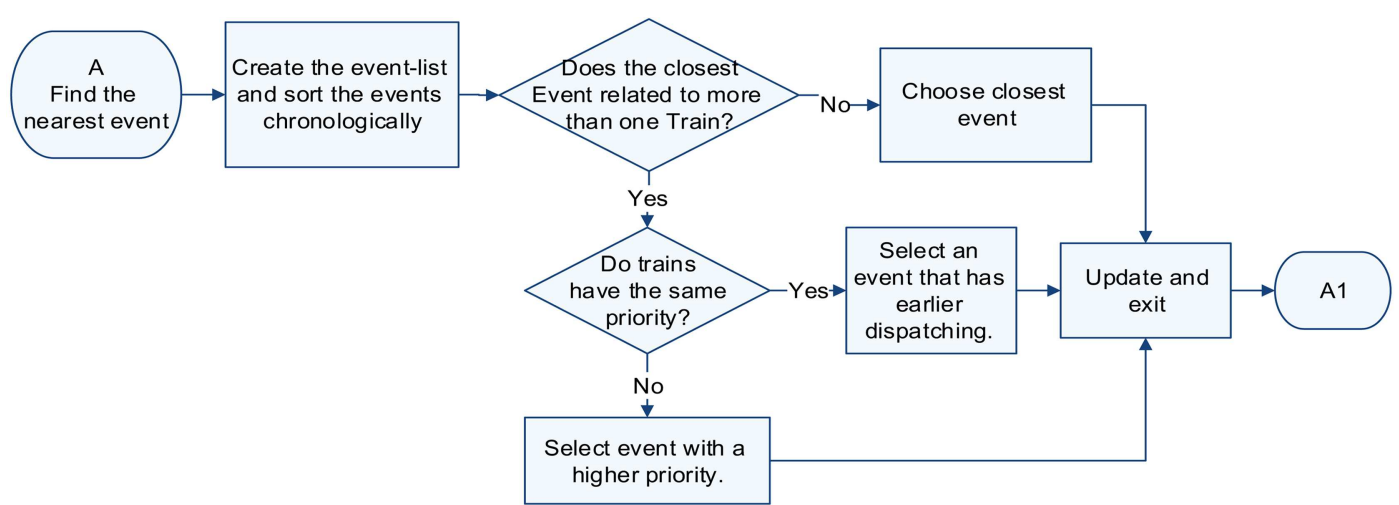

Figure 3. Diagram of the train movement simulation (Part 1: Selection of the next event, according to the event calendar).

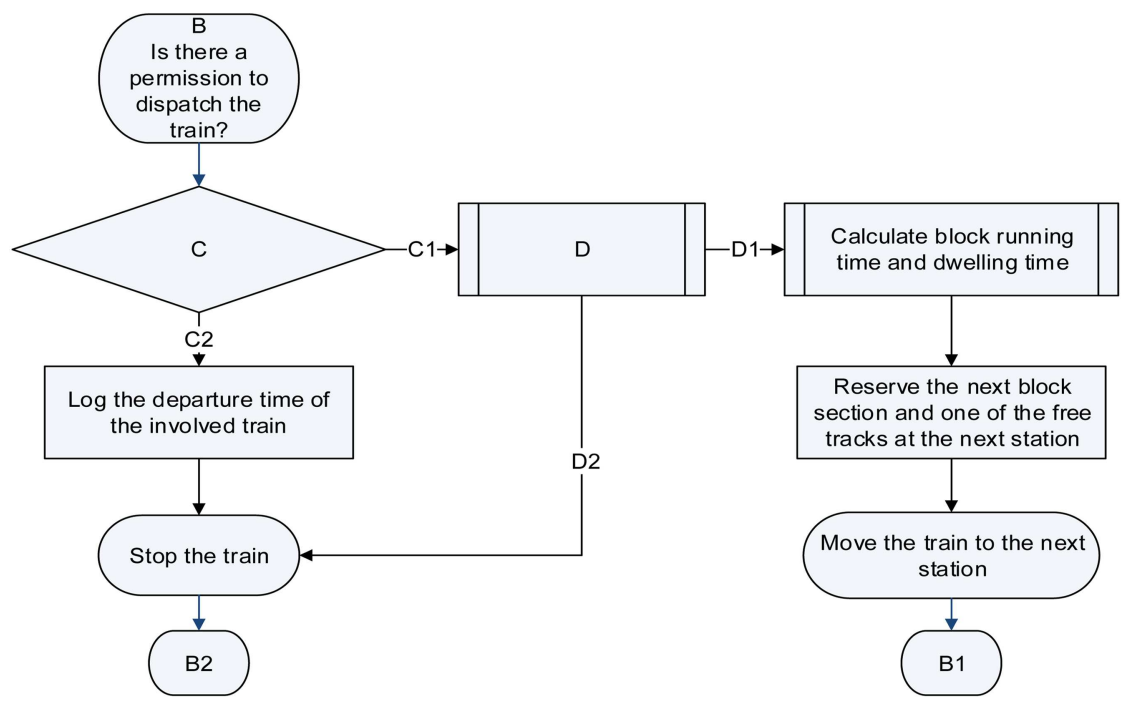

Figure 4. Diagram of the train movement simulation (Part 2: Train timetable calculations).

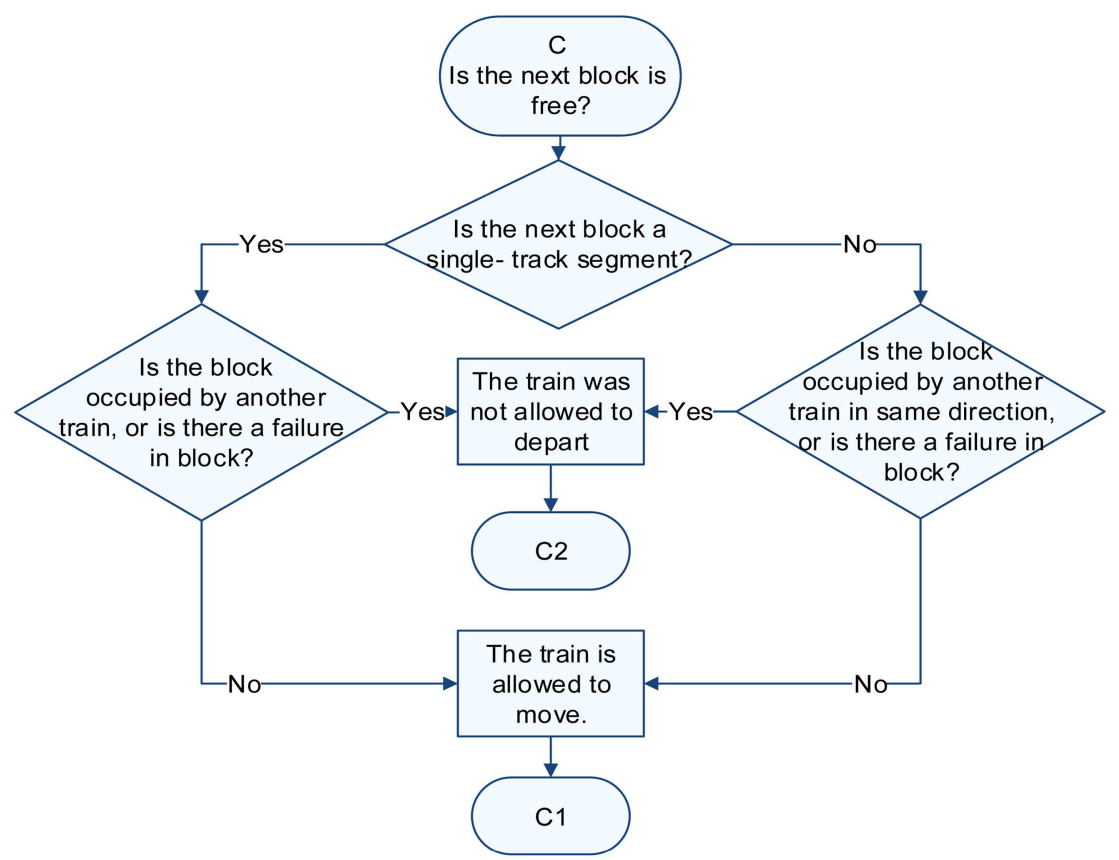

Figure 5. Diagram of the train movement simulation (Part 3: The train departure authorization). 


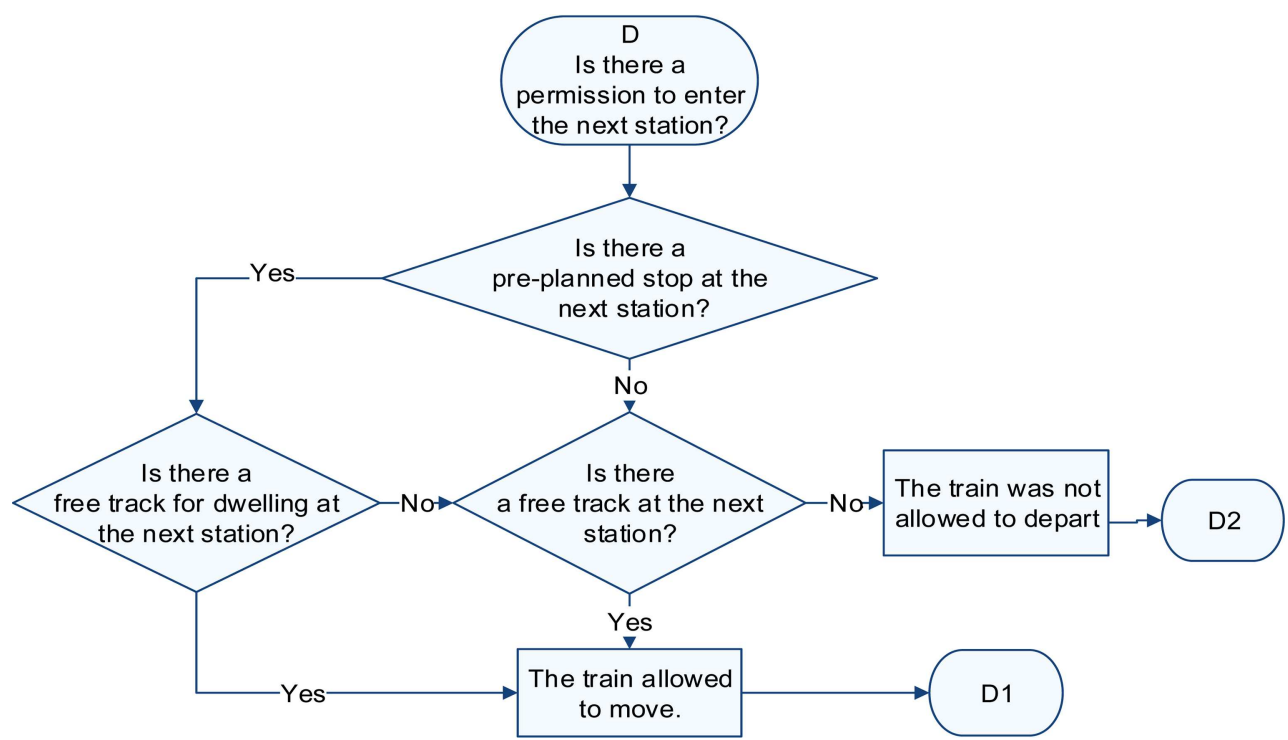

Figure 6. Diagram of the train movement simulation (Part 4: Train stop control).

toward train operation modeling is to construct train timetables. The blocks' occupancy depends on the priority of trains. Duration of dwelling time at a station for a train is calculated as Eq. (1):

Dwelling time duration at a station

$$
=\max \{S, P, F\}+R
$$

where

- $S$ denotes scheduled dwelling time, including boarding and alighting of passengers, refueling, water refilling, etc.;

- $P$ denotes the duration of the pray service (if a stop is scheduled for pray service);

- $F$ denotes failure maintenance time in the stochastic simulation condition (assuming that agents detect the problem at the moment of arrival);

- $R$ denotes the required time to avoid crossing and overtaking calculated by the simulator.

For a train to depart from a station and enter to the next connecting block, block switches are controlled at first. In single-track blocks, the railroad switches must be controlled in both directions, while, in doubletrack blocks, only the one in the same direction must be checked. The train's timetable can be constructed using the developed simulation system.

\subsection{Data input modeling}

\subsubsection{Running times distribution}

According to the disturbances in train movements along the route, running time on the blocks generally vary with their scheduled running time and can be considered as a random variable. In fact, both factors of structural and operational characteristics are effective in this regard. The actual running time for a single train is a function of some factors, e.g., the length of the segment, weather conditions, train loads, and the train operator's behavior. The actual running time of a train may deviate from the scheduled one and result in an extra delay. An important cause of the deviation is the random failures related to the locomotive driver who becomes unable to take the train to the destination on time (due to random variables such as a train breakdown or debris on the track or other driving conditions). In this condition, the central controlling system's commands are communicated, e.g., acceleration or deceleration commands, to the driver in order to minimize train delays.

In order to find an appropriate statistical distribution of this random variable, the running time information of all trains on different blocks of the routes was collected over a three-month time period, and statistical tests for the best distribution fitting for all of the blocks were carried out separately. Actual running time in each block was obtained by subtracting the train's "departure time from one station "from" the arrival time to the next station". Frequency distribution of these delays on blocks separated by different scheduled running times of the trains on each block for each round-trip route was determined. An example of results for a specific block is shown in Figure 7. The result of $\mathrm{KS}$ and Chi-square tests are provided in Box I. Statistical analysis indicated that the running time distribution does not depend on the time of the day.

In order to find the probability distribution function of random failures, a number of observations are required to discover if the actual running time is more than the scheduled one is. The superfluous traveling times are most likely due to the occurrence of damage or unusual happenings during the train's passage on 


\begin{tabular}{|c|c|c|c|}
\hline \multicolumn{2}{|l|}{ Distribution summary } & \multicolumn{2}{|l|}{ Data summary } \\
\hline Distribution: & $=$ Normal & Number of data points & $=88$ \\
\hline Expression: & $=\operatorname{Normal}(15.3,1.54)$ & Min data value (minutes) & $=11$ \\
\hline Square error: & $=0.025822$ & Max data value (minutes) & $=19$ \\
\hline & & Sample Std Dev & $=1.54$ \\
\hline \multirow{2}{*}{\multicolumn{4}{|c|}{$\begin{array}{l}\text { Chi-square test } \\
\text { Number of intervals }\end{array}$}} \\
\hline & & & \\
\hline Degrees of freedom & $=2$ & Range & $=10.5$ to 19.5 \\
\hline Test statistic & $=12.1$ & Number of intervals & $=9$ \\
\hline Corresponding $p$-value & $>0.005$ & & \\
\hline
\end{tabular}

Box I

Table 2. The result of fitting for different block sections.

\begin{tabular}{ccccccccc}
\hline Route & Normal & Beta & Erlang & Weibull & Gamma & Triangular & Exponential & Total \\
\hline Inbound & 28 & 5 & 5 & 3 & 3 & 1 & 3 & 49 \\
Outbound & 26 & 4 & 6 & 3 & 9 & 1 & 0 & 49 \\
\hline
\end{tabular}

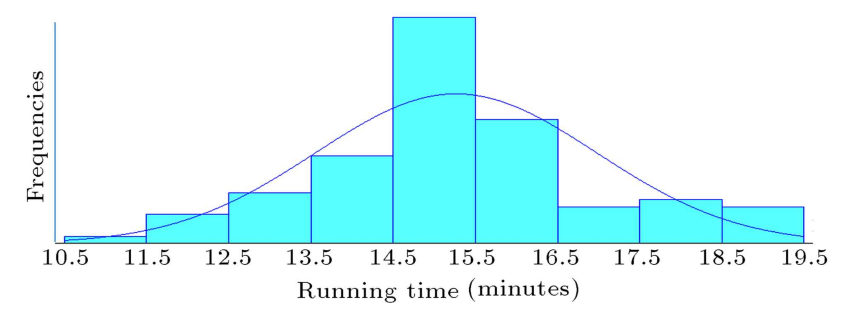

Figure 7. An example of histogram of the running time.

the block. The failure data in every block segments and their impacts on running times are extracted from the database. Table 2 shows the summarized results of these test experiments. This graph demonstrates the occurrence frequency of normal probability distribution as the best fit. A review of the results showed that, in almost $60 \%$ of observations, the best-fitted distribution to the block running times is the normal distribution for all blocks. The tests conducted on other blocks, where normal distribution did not result in better distribution, still showed that a normal distribution could also be accepted with very good fitness in these same blocks. Accordingly, the normal distribution is selected as the distribution of the block running times in this study.

\subsubsection{Distribution of dwelling times}

The same type of statistical analysis has completed dwelling time at stations. A train's dwelling time at stations is usually respected according to the regulated schedule; however, when delays occur, operators try to reduce the total delay by minimizing the dwell time of passengers in the stations. Dwelling time at the station is calculated by subtracting the train's "arrival time to the station" from "the departure time from the same station." The dwelling time is generally observed according to the timetable; however, when there are delays in train movement, attempt is made to decrease the total delay by minimizing stop times at stations. The actual stop time at stations equals the sum of scheduled stop time and random part related to delay. Thus, the stop time can be calculated using the departure and arrival times. The data analysis shows that the difference between real stop time at the station and its scheduled time in Tehran-Mashhad route changes from -2 to 5 minutes, approximately. The theoretical probability function of this difference is determined. According to the obtained result (Table 3), Erlang distribution is chosen as the best distribution describing the data.

In order to obtain the probability distribution of the dwelling times, the differences in actual dwelling time at stations are computed and compared to the scheduled time for the Tehran-Mashhad corridor. The probability function of this difference has been determined using the Arena input analyzer toolbox and Erlang distribution, selected as the best tools for

Table 3. The result of fitting for dwelling time.

\begin{tabular}{ccccccccc}
\hline Route & Normal & Beta & Erlang & Weibull & Gamma & Triangular & Exponential & Total \\
\hline Inbound & 4 & 2 & 32 & 5 & 3 & 1 & 3 & 50 \\
Outbound & 2 & 4 & 29 & 7 & 5 & 1 & 2 & 50 \\
\hline
\end{tabular}




\begin{tabular}{|c|c|c|c|}
\hline \multicolumn{2}{|c|}{ Distribution summary } & \multicolumn{2}{|l|}{ Data summary } \\
\hline Distribution: & $=$ Erlang & Number of data points & $=4809$ \\
\hline Expression: & $=-5.5+\operatorname{ERLA}(0.8567)$ & Sample mean & $=0.492$ \\
\hline Square error: & $=0.161$ & Sample Std Dev & $=2.51$ \\
\hline
\end{tabular}

Box II

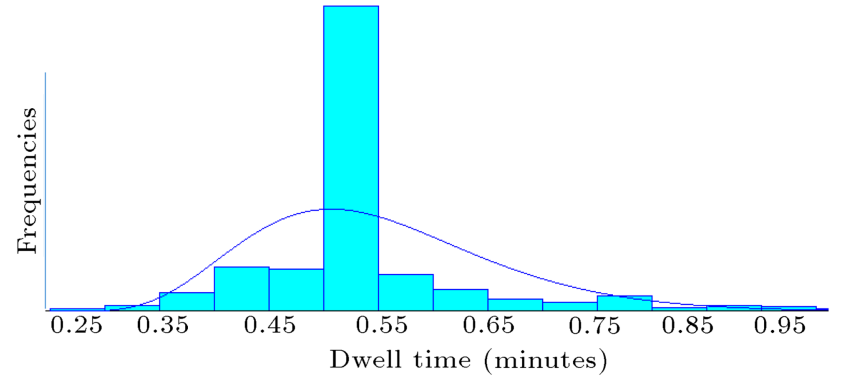

Figure 8. An example of histogram of dwelling time delays at the station.

describing the distribution of these data. Figure 8 shows the frequency of delays for both routes. The coefficients of the Erlang distribution function, however, are different for various stations. The result of KS and Chi-square tests for dwell time distribution are provided in Box II. According to the route-cause analysis, the dwelling time deviation is affected by driver faults. In the case of deviation from the initial plan, the central control commands to compensate for the occurred delays in disturbances.

\subsubsection{Failure modeling on the block sections}

Simulation models are capable of modeling disturbances of running times in the schedules. The data required to calculate the probability of failures are prepared according to the historical database. When a train fails at a station, it causes a primary delay. Figure 9 illustrates the frequency of train failures on the blocks of the Tehran-Mashhad route. The result of KS and Chi-square tests for failure time distribution are provided in Box III. As seen, these events occur heterogeneously along the route. The probabilities of failure

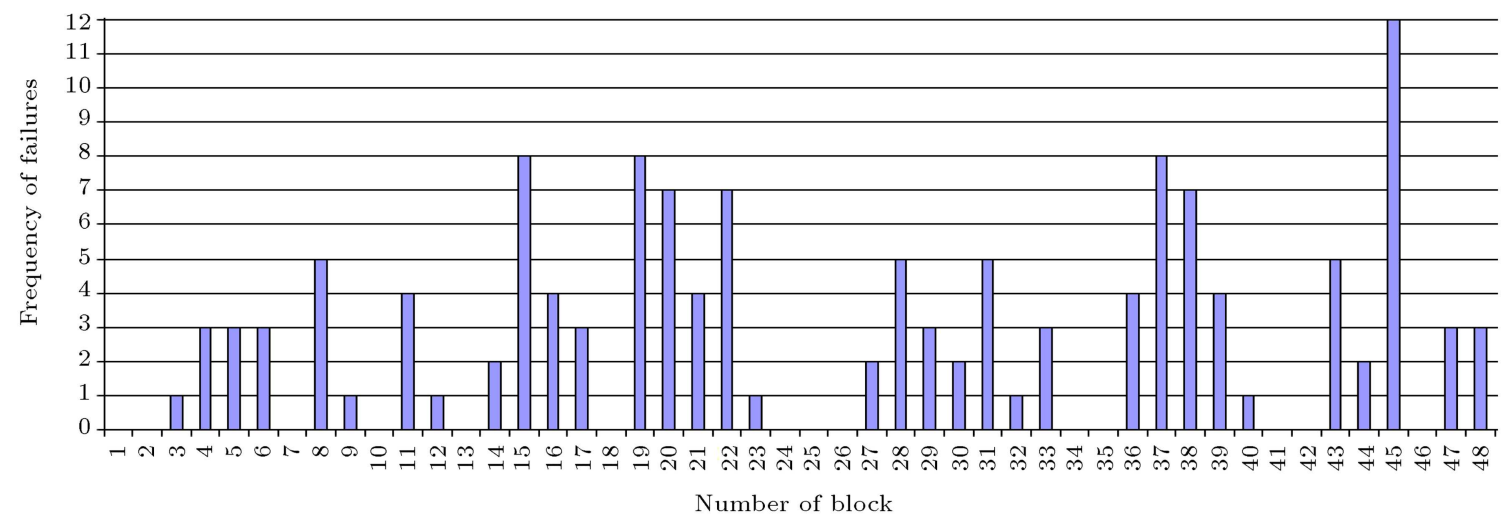

(a)

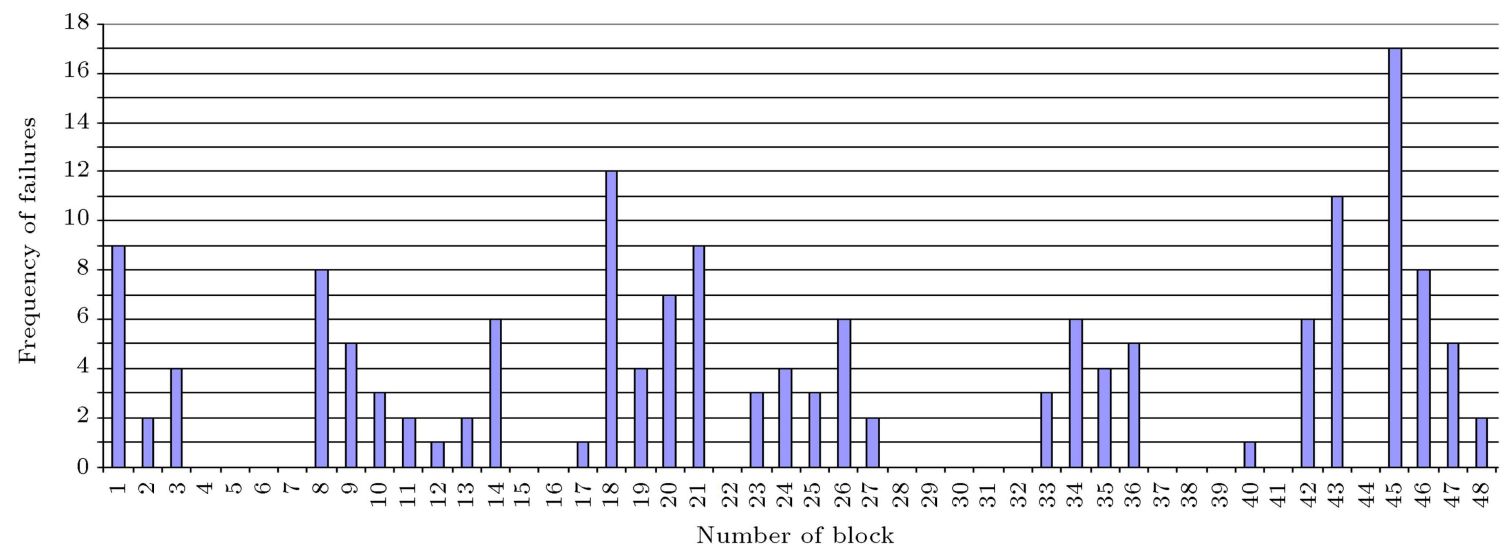

(b)

Figure 9. Diagram of failure occurrences on blocks: (a) Inbound trains and (b) outbound trains. 


\begin{tabular}{|c|c|c|c|}
\hline \multicolumn{2}{|c|}{ Distribution summary } & \multicolumn{2}{|l|}{ Kolmogorov-smirnov test } \\
\hline Distribution: & $=$ Weibull & Test statistic & $=0.19$ \\
\hline Expression: & $=25+$ WEIB $(25.6,0.526)$ & Corresponding $p$-value & $>0.1$ \\
\hline Square error: & $=0.034497$ & & \\
\hline
\end{tabular}

in a block section for fast non-electric trains, other non-electric trains, and electric trains are calculated as $0.35 \%, 0.6 \%$, and $0.15 \%$, respectively. Likewise, the average failure durations are 21, 27, and 15 minutes, respectively.

\subsubsection{Failure modeling in the stations}

The probability of random failures at the stations has been calculated for two train categories through examining the existing data of the Tehran-Mashhad route. It is observed that the failure probability of the non-electric high-speed train is $0.15 \%$, while, for other trains, the amount is $0.4 \%$. Furthermore, for the electric trains, the probability of a failure at a particular station is observed by $0.09 \%$. Various tests on the available data show that trains' dwell in times in such cases follow the Weibull distribution. Figure 10 shows a diagram of the mentioned processed data.

In order to determine the failure events at stations, the probability of occurrence of these events is calculated for different classes of trains (Table 4). The outcomes of the test experiments on the real data demonstrate that the failure at station conforms to the Weibull probability distribution.

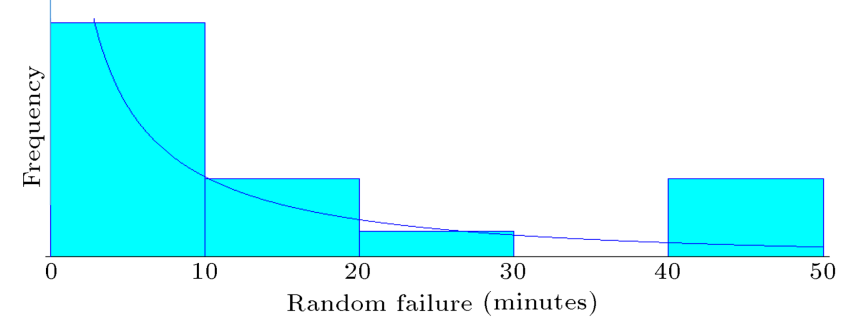

Figure 10. Histogram of random failure times at the station (Tehran-Mashhad corridor).

\subsection{Reliability assessment}

Assuming that the movement of each train from the origin is based on the given schedule, the reliability of a train movement can be obtained through the comparison of the train arrival delay with allowable delay. However, the train arrival or departure time is supposed to be a constant; however, in practice, trains are affected by failure and disruptions. These disruptions generate delays in trains schedule and also affect the timetable of the other trains. In this paper, the train reliability criterion is calculated using Eq. (2). It calculates the percentage of trains arrived at a destination within the allowable delay range:

$$
\begin{aligned}
& r=1-\frac{\sum_{i=1}^{m} \gamma_{i} N_{A f(i)}^{i}+\sum_{j=m}^{n} \gamma_{j} \hat{N}_{A f(j)}^{j}}{n} \\
& i \in I, \quad j \in J .
\end{aligned}
$$

In the above equation, index $i$ represents the departing train and index $j$ represents the arriving trains which is a member of index set of $J$, and $n$ represents the number of trains. Numbers of inbound and outbound trains are $m$ and $n-m$, respectively. The importance weight of train $i$ is denoted by $\gamma_{i}$. Let $f(i)$ and $f(j)$ denote the destinations of the departing train $i(i \in I)$ and arriving train $j(j \in J)$, respectively. Furthermore, $n_{A f(i)}^{i}$ and $\hat{n}_{A f(j)}^{j}$ show the maximum allowable delays of trains $i$ and $j$, arriving at their destinations. For each train, the rail operator decides the allowable delay of arrival. Variables $N_{A f(i)}^{i}$ and $\hat{N}_{A f(j)}^{j}$ are defined as follows:

$$
N_{A f(j)}^{j}= \begin{cases}1 & \begin{array}{l}
\text { if forward train } i \text { has a delay smaller } \\
\text { than } n_{A f(i)}^{i} \text { in destination } f(i) \\
0 \quad \text { otherwise }
\end{array}\end{cases}
$$

Table 4. The results of failure modeling for different class of trains.

\begin{tabular}{ccccccc}
\hline \multirow{2}{*}{ Type of train } & \multicolumn{2}{c}{ Failure at block sections } & & \multicolumn{2}{c}{ Failure at stations } \\
\cline { 2 - 3 } & $\begin{array}{c}\text { The occurrence } \\
\text { probability }\end{array}$ & $\begin{array}{c}\text { Average failure } \\
\text { duration (minutes) }\end{array}$ & & $\begin{array}{c}\text { The occurrence } \\
\text { probability }\end{array}$ & $\begin{array}{c}\text { Probability } \\
\text { distribution }\end{array}$ \\
\hline $\begin{array}{c}\text { Non-electric } \\
\text { high-speed train }\end{array}$ & $0.35 \%$ & 21 & & $0.15 \%$ & Weibull \\
Other non-electric trains & $0.6 \%$ & 27 & & & $0.4 \%$ & Weibull \\
Electric train & $0.15 \%$ & 15 & & $0.09 \%$ & Weibull \\
\hline
\end{tabular}




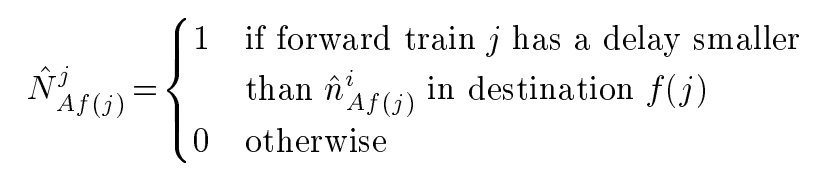

The reliability index in the $k$ th replication is denoted by $r_{k}$. The reliability $(R)$ is calculated after system simulation for a number of replications $(n)$, and the expected value can be calculated through Eq. (3). The reliability of the train timetable is measured based on probabilistic information of train's delay.

$$
R=\frac{\sum_{k=1}^{n} r_{k}}{n}
$$

\section{Case study}

The Islamic Republic of Iran Railways (IRIR) is a national state-owned railway system. Some 33 million tons of goods and 29 million passengers are transported annually by the rail transportation network, accounting for $11 \%$ of the whole transportations in Iran. In this study, Tehran-Mashhad route is selected as a case study (Figure 11). The Tehran-Mashhad route is the country's most important rail corridor for passenger trains and consists of 49 stations. Although both passenger and cargo trains are operating in this route, passenger trains share is more than $85 \%$, and, annually, around 20 million passengers are traveling along this route.

\subsection{Input data}

The developed simulation model has several data inputs given as follows: infrastructure, train operation, timetable, and simulation conditions. Their details are stated below:

- Infrastructure data: Data related to the railway infrastructure include the scheme of a railway route, the distance between the stations, the location of the crossing loops, the number of tracks, the type of the block segments, and failure probability of the track segments. Based on the infrastructure data, the simulation model is developed that allows full train movement simulation along the route. The infrastructure data of Tehran-Mashhad corridor are summarized in Table 5;

- Operational data: The input data for our train operation model contain the train route (origin and

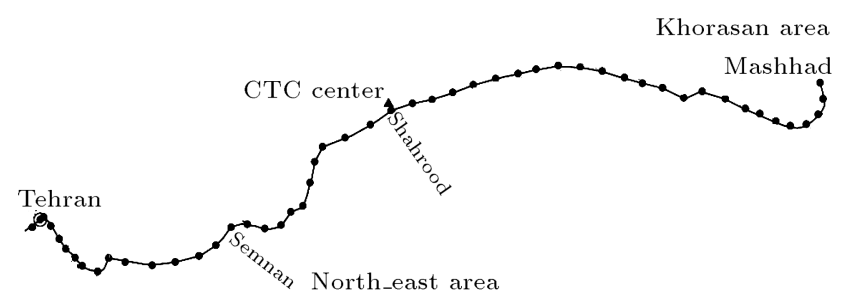

Figure 11. Tehran-Mashhad double-track route. destination), train priorities, delay penalty for delay of each train, stochastic running times on block sections as well as dwelling time at stations;

- Timetable data: The departure time of the trains from their origins and the planned arrival times at each station are the data associated with train timetables;

- Simulation conditions data: In order to simulate the trajectory of the train along the railway network, some parameters must be decided to obtain valid results. The simulation parameters include the observation period, the number of replications, and the desirable accuracy of the simulation outputs $(95 \%)$.

\subsection{Data Processing}

This section provides input data modeling using records of train data. The historical data of train movements include the real circulation time in blocks and the entire route, the real time of stops at stations, the reason of stops, and frequency of failures; these data exist in the control center of the Railroad Company. Trains' scheduling data include departure time, scheduled block time, scheduled dwelling time, as well as the praying services. This study considers trains as recipient services and every station and block as the server.

In order to compare electric and non-electric systems, both cases should be modelled in the same system. According to the existing situation and the available data of the non-electric Tehran-Mashhad route, the required operational parameters of the electrified rail system should be derived. It is required to derive probability distribution functions of running time at block sections, dwelling time at stations and failures at blocks and stations. It should be noted that the comparative analysis of the electrified and non-electrified cases must be performed under similar operating conditions. Thus, the extracted parameters of electrified train (Tabriz-Jolfa route) have been adopted for the simulation model of Tehran-Mashhad route. The extracted parameters are the random operational data of Tabriz-Jolfa route in the electric mode. These parameters include random failures in the block segments and rail stations, dwelling time at stations, and running times of trains on block sections. The best-fitted distribution of the abovementioned parameters is determined through the least squares error method. This tool calculates probability distribution parameters and the statistic of Chi-square and Kolmogorov-Smirnov (KS) tests. In order to find an appropriate statistical distribution for random variables, data of different real block times of all the trains on the route were gathered for three months. The results of fitting of running time distribution for the Tehran-Mashhad corridor are presented in the last 
Table 5. The operational, infrastructure, and running time distribution data of Tehran-Mashhad route.

\begin{tabular}{|c|c|c|c|c|c|c|c|c|c|}
\hline \multirow{2}{*}{$\begin{array}{c}\text { Block } \\
\text { number }\end{array}$} & \multirow{2}{*}{$\begin{array}{c}\text { Block } \\
\text { length } \\
(\mathrm{km})\end{array}$} & \multirow{2}{*}{$\begin{array}{c}\text { Number } \\
\text { of } \\
\text { tracks }\end{array}$} & \multicolumn{2}{|c|}{$\begin{array}{c}\text { Planned running } \\
\text { time (minutes) }\end{array}$} & \multicolumn{2}{|c|}{$\begin{array}{l}\text { Maximum block } \\
\text { speed (km/hour) }\end{array}$} & \multicolumn{2}{|c|}{$\begin{array}{c}\text { Running time } \\
\text { parameters }\end{array}$} & \multirow{2}{*}{$\begin{array}{l}\text { Best fitted } \\
\text { running time } \\
\text { distribution }\end{array}$} \\
\hline & & & Inbound & Outbound & Inbound & Outbound & $\begin{array}{c}\text { Average } \\
\text { (minutes) }\end{array}$ & $\begin{array}{l}\text { Standard } \\
\text { (minutes) }\end{array}$ & \\
\hline 1 & 9.9 & Double & 15 & 14 & 40 & 40 & 15.90 & 2.7 & Normal \\
\hline 2 & 16.5 & Double & 12 & 13 & 115 & 90 & 12.92 & 1.5 & Normal \\
\hline 3 & 17.4 & Double & 12 & 13 & 115 & 90 & 13.51 & 1.8 & Beta \\
\hline 4 & 8.8 & Double & 9 & 10 & 115 & 90 & 8.86 & 2 & Normal \\
\hline 5 & 12 & Double & 9 & 10 & 115 & 90 & 9.30 & 9 & Erlang \\
\hline 6 & 17 & Double & 15 & 20 & 115 & 90 & 15.34 & 3.1 & Normal \\
\hline 7 & 17 & Double & 16 & 20 & 115 & 90 & 17.31 & 3.3 & Normal \\
\hline 8 & 17 & Single & 12 & 12 & 115 & 115 & 13.52 & 2 & Gamma \\
\hline 9 & 21.9 & Single & 12 & 12 & 115 & 115 & 13.58 & 2.1 & Triangular \\
\hline 10 & 15.5 & Single & 11 & 11 & 115 & 115 & 10.30 & 1.9 & Normal \\
\hline 11 & 20.5 & Single & 13 & 11 & 115 & 115 & 12.32 & 1.8 & Weibull \\
\hline 12 & 21.2 & Single & 12 & 12 & 115 & 115 & 14.97 & 2.3 & Erlang \\
\hline 13 & 18 & Single & 13 & 13 & 115 & 115 & 15.61 & 2.2 & Normal \\
\hline 14 & 18.5 & Single & 13 & 12 & 110 & 110 & 15.20 & 2 & Exponential \\
\hline 15 & 16.3 & Single & 14 & 12 & 90 & 90 & 15.64 & 1.8 & Normal \\
\hline 16 & 15.5 & Single & 15 & 12 & 70 & 70 & 14.18 & 2.1 & Normal \\
\hline 17 & 15.1 & Single & 15 & 13 & 70 & 70 & 16.78 & 2.2 & Normal \\
\hline 18 & 14 & Single & 12 & 15 & 70 & 70 & 14.44 & 2.5 & Normal \\
\hline 19 & 12.8 & Single & 12 & 13 & 70 & 70 & 12.17 & 2.8 & Normal \\
\hline 20 & 13.5 & Single & 10 & 14 & 70 & 70 & 11.16 & 2.4 & Beta \\
\hline 21 & 15.9 & Double & 10 & 10 & 115 & 115 & 10.95 & 2.1 & Weibull \\
\hline 22 & 14.3 & Double & 10 & 10 & 115 & 115 & 11.04 & 1.7 & Normal \\
\hline 23 & 22.8 & Double & 13 & 14 & 115 & 115 & 14.86 & 2.7 & Normal \\
\hline 24 & 23.8 & Double & 14 & 13 & 115 & 115 & 15.85 & 1.8 & Erlang \\
\hline 25 & 18.9 & Double & 15 & 13 & 115 & 115 & 17.09 & 2.6 & Normal \\
\hline 26 & 20.6 & Double & 13 & 13 & 115 & 115 & 13.37 & 2.5 & Normal \\
\hline 27 & 20.3 & Double & 12 & 12 & 115 & 115 & 13.03 & 1.7 & Gamma \\
\hline 28 & 18.3 & Single & 12 & 12 & 115 & 115 & 11.59 & 1.5 & Normal \\
\hline 29 & 20.6 & Single & 12 & 12 & 115 & 115 & 13.88 & 1.7 & Normal \\
\hline 30 & 22.2 & Single & 15 & 13 & 115 & 90 & 14.60 & 2.3 & Beta \\
\hline 31 & 19.5 & Single & 15 & 14 & 90 & 90 & 14.38 & 1.6 & Erlang \\
\hline 32 & 22.2 & Single & 18 & 18 & 80 & 80 & 18.99 & 3 & Normal \\
\hline 33 & 20.2 & Single & 15 & 15 & 90 & 90 & 17.37 & 2.6 & Weibull \\
\hline 34 & 19.5 & Double & 13 & 14 & 115 & 90 & 16.82 & 2.5 & Normal \\
\hline 35 & 19.2 & Double & 13 & 14 & 115 & 90 & 13.72 & 2.6 & Exponential \\
\hline 36 & 23.3 & Double & 15 & 17 & 115 & 90 & 15.86 & 3.9 & Normal \\
\hline 37 & 20.5 & Double & 13 & 15 & 115 & 90 & 12.30 & 2.4 & Erlang \\
\hline 38 & 20.4 & Double & 13 & 15 & 115 & 90 & 16.09 & 2 & Normal \\
\hline 39 & 22.6 & Double & 15 & 18 & 115 & 90 & 16.79 & 1.9 & Normal \\
\hline 40 & 23.6 & Single & 19 & 19 & 80 & 80 & 18.75 & 1.6 & Gamma \\
\hline 41 & 23.6 & Single & 19 & 19 & 80 & 80 & 18.41 & 1.8 & Exponential \\
\hline 42 & 22.1 & Single & 19 & 19 & 80 & 80 & 18.79 & 3.4 & Normal \\
\hline
\end{tabular}


Table 5. The operational, infrastructure and running time distribution data of Tehran-Mashhad route (continued).

\begin{tabular}{|c|c|c|c|c|c|c|c|c|c|}
\hline \multirow{2}{*}{$\begin{array}{c}\text { Block } \\
\text { number }\end{array}$} & \multirow{2}{*}{$\begin{array}{c}\text { Block } \\
\text { length } \\
(\mathbf{k m})\end{array}$} & \multirow{2}{*}{$\begin{array}{c}\text { Number } \\
\text { of } \\
\text { tracks }\end{array}$} & \multicolumn{2}{|c|}{$\begin{array}{c}\text { Planned running } \\
\text { time (minutes) }\end{array}$} & \multicolumn{2}{|c|}{$\begin{array}{l}\text { Maximum block } \\
\text { speed (km/hour) }\end{array}$} & \multicolumn{2}{|c|}{$\begin{array}{c}\text { Running time } \\
\text { parameters }\end{array}$} & \multirow{2}{*}{$\begin{array}{l}\text { Best fitted } \\
\text { running time } \\
\text { distribution }\end{array}$} \\
\hline & & & Inbound & Outbound & Inbound & Outbound & $\begin{array}{c}\text { Average } \\
\text { (minutes) }\end{array}$ & $\begin{array}{l}\text { Standard } \\
\text { (minutes) }\end{array}$ & \\
\hline 43 & 22.2 & Single & 19 & 19 & 80 & 80 & 20.14 & 2.7 & Normal \\
\hline 44 & 23.2 & Single & 19 & 19 & 80 & 80 & 18.59 & 1.9 & Normal \\
\hline 45 & 17.4 & Single & 15 & 16 & 80 & 80 & 17.54 & 2.1 & Beta \\
\hline 46 & 18.6 & Single & 16 & 17 & 80 & 80 & 18.24 & 3 & Normal \\
\hline 47 & 18.8 & Single & 16 & 19 & 80 & 80 & 19.33 & 3.8 & Normal \\
\hline 48 & 18.5 & Double & 14 & 19 & 115 & 80 & 13.76 & 2.1 & Beta \\
\hline
\end{tabular}

column of Table 5. The outcomes show that, in almost $60 \%$ of all cases, the normal distribution is the bestfitted distribution for running times.

After accepting normal distribution as an appropriate travelling time distribution for blocks, the next problem would be estimating the parameters of this distribution (mean and standard deviation) for different blocks. Obviously, various factors influenced the mean value and standard deviation of travelling times on blocks. In this study, different factors, such as maximum slope, summation of curve degrees in the block and others, were considered; then, linear regression was used to calculate the actual average travelling time of electric and non-electric trains in each block. The following simple equations were fitted and suggested:

$$
\begin{aligned}
& \text { Average travel time } \text { Electric trains }=0.614_{(t=0.434)} \\
& \quad+0.904_{(t=16.046)} \times(\text { Scheduled travel time }) \\
& R^{2}=0.97
\end{aligned}
$$

Average travel time $\mathrm{non-Electric} \mathrm{trains}=1.996_{(t=1.027)}$

$$
\begin{aligned}
& \quad+0.929_{(t=7.129)} \times(\text { Scheduled travel time }), \\
& R^{2}=0.836 .
\end{aligned}
$$

In these equations, mean value of actual travelling time is assumed a linear function of scheduled travelling time. Scheduled travelling time is the time calculated by the railway administration office for each block. Considering results obtained from several studies and experiments to estimate the standard deviation of travelling time on blocks, it is not possible to suggest an acceptable equation for travelling time standard deviation of blocks in terms of different parameters. The approach to estimating the standard deviation of travelling times of blocks is to assume this amount as random and estimate a suitable distribution function to represent it. Therefore, a method for estimating a suitable distribution function for the standard deviation of travelling times of blocks was developed. Experiments revealed that the normal distribution with a mean value of 1.93 and standard deviation of 0.7 for electric trains and an average mean value of 2.39 and standard deviation of 0.79 for non-electrical trains are a suitable distribution for these parameters. If this calculation is accepted, the proposed method to estimate standard deviation for each block in the simulation model will produce normal random variables with the mentioned characteristics, and it should be applied to every simulation model repetition.

\section{Result and discussion}

This section outlines the experimental results obtained by running our simulation model through several test cases. Four various tests with random parameters were used to determine the trains' movement reliability (Table 6). These tests were analyzed in two cases regarding the number of tracks. The first case refers to the situation when the segments of the TehranMashhad route are of partially single and double tracks (past situation). There are only 21 double-track blocks in the entire network and the rest are single-track. The second case refers to the layout in which the entire route is double-tracked. In this case, the number of stops for crossing and overtaking decreases significantly. This separation was made in order to compare the difference

Table 6. Characteristics of the test experiments.

\begin{tabular}{ccc}
\hline Rail infrastructure & Non-electrified & Electrified \\
\hline Partially single and double-track & Test 1 & Test 2 \\
Complete double-track & Test 3 & Test 4 \\
\hline
\end{tabular}


between partially single- and double-tracked cases and a complete double-track situation. Regarding the type of traction, test experiments are divided into electrified and non-electrified. In the case of non-electrified experiment, Tehran-Mashhad data were used. For the electrified one, the processed data of Tabriz-Jolfa electrified route were implemented in Tehran-Mashhad route. As shown in Table 6, Tehran-Mashhad blocks in the first and second tests were combined; in the third and fourth tests, the whole route changed to a doubletrack route. On the other hand, the first and third tests were done on the non-electrified system, and the second and forth tests for the electrified system. In all test experiments, the failure at blocks and stations was considered.

\subsection{Verification}

The simulation model was executed for $n=100$ replications. Table 7 provides the values of reliability per given amount of delay for electric and non-electric systems. As shown in Figure 12, the advantage of the double-track case over the single- and double-track cases is significant. For example, for an allowable delay of 56 minutes, the reliability of Test 3 is almost $200 \%$ better than that of Test 1 , meaning that doubling can greatly improve the reliability of train movements. As can be seen, for an allowable delay of 56 minutes, the

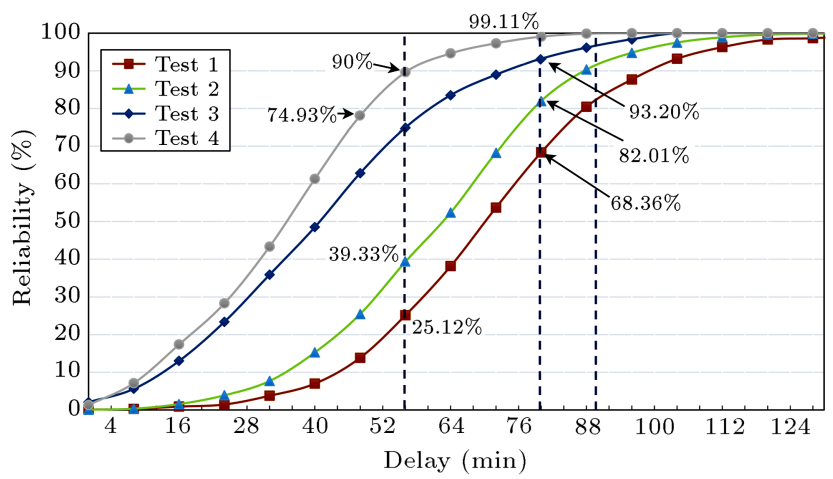

Figure 12. Average reliability per given amount of delay.

electrification of the railway has resulted in a $14 \%$ improvement in reliability. One of the important applications of reliability is calculating the penalties paid by railway companies for delays more than allowable delay to passengers. According to the Iranian railway company, if the actual delay is beyond the allowed delay, then the whole ticket fee must be paid back to the passengers. For the case when the allowable delay is 56 minutes, the rail company does not have to pay the penalties to a passenger with the probabilities of $25.1 \%, 39.3 \%, 74.9 \%$, and $90.0 \%$ in Tests $1,2,3$, and 4, respectively (Figure 12). Currently, the TehranMashhad route is a complete double-track line and non-

Table 7. Different values of reliability for various test cases.

\begin{tabular}{|c|c|c|c|c|}
\hline \multirow{4}{*}{$\begin{array}{c}\text { Allowed } \\
\text { delay } \\
\text { (minutes) }\end{array}$} & \multicolumn{4}{|c|}{ Reliability } \\
\hline & \multicolumn{2}{|c|}{ Partially single and double-track section } & \multicolumn{2}{|c|}{ Complete double-track } \\
\hline & Non-electrified & Electrified & Non-electrified & Electrified \\
\hline & Test 1 & Test 2 & Test 3 & Test 4 \\
\hline 0 & $0.10 \%$ & $0.06 \%$ & $2.07 \%$ & $1.33 \%$ \\
\hline 8 & $0.25 \%$ & $0.35 \%$ & $5.59 \%$ & $7.12 \%$ \\
\hline 16 & $0.88 \%$ & $1.56 \%$ & $13.00 \%$ & $17.38 \%$ \\
\hline 24 & $1.43 \%$ & $3.88 \%$ & $23.37 \%$ & $28.29 \%$ \\
\hline 32 & $3.76 \%$ & $7.69 \%$ & $35.90 \%$ & $43.38 \%$ \\
\hline 40 & $6.97 \%$ & $15.27 \%$ & $48.53 \%$ & $61.33 \%$ \\
\hline 48 & $13.84 \%$ & $25.45 \%$ & $62.84 \%$ & $78.11 \%$ \\
\hline 56 & $25.12 \%$ & $39.33 \%$ & $74.93 \%$ & $89.66 \%$ \\
\hline 64 & $38.17 \%$ & $52.40 \%$ & $83.54 \%$ & $94.65 \%$ \\
\hline 72 & $53.69 \%$ & $68.25 \%$ & $88.97 \%$ & $97.34 \%$ \\
\hline 80 & $68.36 \%$ & $82.01 \%$ & $93.20 \%$ & $99.11 \%$ \\
\hline 88 & $80.49 \%$ & $90.34 \%$ & $96.16 \%$ & $99.88 \%$ \\
\hline 96 & $87.72 \%$ & $94.80 \%$ & $98.37 \%$ & $100.00 \%$ \\
\hline 104 & $93.22 \%$ & $97.51 \%$ & $100.00 \%$ & $100.00 \%$ \\
\hline 112 & $96.31 \%$ & $98.90 \%$ & $100.00 \%$ & $100.00 \%$ \\
\hline 120 & $98.33 \%$ & $99.60 \%$ & $100.00 \%$ & $100.00 \%$ \\
\hline 128 & $98.68 \%$ & $99.83 \%$ & $100.00 \%$ & $100.00 \%$ \\
\hline 136 & $99.34 \%$ & $99.88 \%$ & $100.00 \%$ & $100.00 \%$ \\
\hline
\end{tabular}


electric trains are operating (as described in Test 3). The travelling time is about 12 hours. In this case, the railway company has determined the allowed delay as 90 minutes. Consequently, it can be determined that the railway company must pay back the passengers with the probability of $4 \%$.

\subsection{Statistical analysis of service reliability}

Due to the stochastic nature of the simulation models, one single outcome is not representative. Therefore, a number of observations are required in order to obtain reliable results with a desirable level of accuracy. The reliability of the result is represented by confidence interval which indicates the probability (usually 95\%) that the output variable is within the range specified. For every performance measure (PFM), an observation $w_{i}$ is collected after each observation period $i$. Each statistic is estimated based on raw data $w_{1}, w_{2}, \ldots, w_{n}$, where $n$ is the number of replications [12]. The lower and upper bounds of the Confidence Interval (CI) are obtained from Eq. (6). Values $t_{n-1,1-\frac{1}{2} \alpha}$ and $\mu_{1-\frac{1}{2} \alpha}$ are obtained from a table of $t$-values, where $\alpha=1-$ Reliability.

$$
C I=\left\{\begin{array}{lc}
\bar{w} \pm t_{n-1,1-\frac{1}{2} \alpha} \cdot \frac{s}{\sqrt{n}} \quad n \leq 30 \\
\bar{w} \pm \mu_{1-\frac{1}{2} \alpha} \cdot \frac{s}{\sqrt{n}} \quad n>30 .
\end{array}\right.
$$

To show further analysis of the reliability, the results of statistical analysis of test experiments are provided in Table 8. As can be seen, the result includes the average and standard deviation of the reliability and a $95 \%$ confidence interval. The outcomes indicate a significant difference between the average reliabilities of the test cases.

\subsection{Train delay's cascading effect along the railway line}

This section provides the interdependency analysis of train delays caused by cascading effect within the rail system. The relations of delays along the rail line by Chi-square independence test and Pearson productmoment correlation test are investigated. The correlation coefficients are then used to describe relations between delay events along the route.

\subsubsection{Independence test}

Independence tests carried out on two variables are independent of each other. In our implementation,
Chi-square independent test is used to measure the paired observations and testify if there is any significant relation between the train delay at one middle station and delays at the subsequent stations. Based on the null hypothesis, the manifestation of these results is statistically independent. Each observation is assigned to one element of a two-dimensional array according to the values of the two outcomes. If there are $r$ rows and $c$ columns in the table, the "theoretical frequency" for an element can be expressed formulaically as follows:

$$
\begin{aligned}
E_{i j}= & \frac{\text { row total } \times \text { column total }}{\text { sample size }} \\
& =\frac{\sum_{n_{c}=1}^{c} O_{i, n_{c}} * \sum_{n_{r}=1}^{r} O_{r, n_{r}}}{N} .
\end{aligned}
$$

In other words, the expected count of each element is calculated by multiplying the marginal row and column totals for that element and dividing them by the total sample size $(N)$. The chi-square test continues by comparing each element's observed count with its corresponding expected count. This chi-square test statistic is then computed as follows:

$$
\chi^{2}=\sum_{1=1}^{r} \sum_{J=1}^{c} \frac{\left(O_{i j}-E_{i j}\right)^{2}}{E_{i j}} .
$$

The decision is made by comparing the value of the test's statistic with a critical value. The critical value for the Chi-square test is $\chi_{\alpha}^{2}$ with degree of freedom $=(r-1) *(c-1)$. According to the statistical analysis, the obtained $P$-value indicates that all independent coefficients are about 0.0159 , which is much less than the significance level (0.05). Thus, it is concluded that there is a strong relationship between train delays at the individual station and delays at the following stations.

\subsubsection{Correlation test}

Pearson product-moment correlation test is performed to determine if there is a correlation between delays at the individual station and those at the following stations. To do so, the correlation coefficient $(r)$ is calculated. This coefficient is defined as the covariance of the two variables separated from the product of their standard deviations. The correlation coefficients are

Table 8. The simulation result of the test experiments for a given delay threshold (64 minutes).

\begin{tabular}{ccccccc}
\hline Test & $\begin{array}{c}\text { Average } \\
\text { reliability }\end{array}$ & $\begin{array}{c}\text { Standard } \\
\text { deviation }\end{array}$ & $\begin{array}{c}\text { Lower bound } \\
\mathbf{( 9 5 \% )}\end{array}$ & $\begin{array}{c}\text { Upper bound } \\
\mathbf{( 9 5 \% )}\end{array}$ & Minimum & Maximum \\
\hline Test 1 & 0.382 & 0.062 & 0.351 & 0.413 & 0.084 & 0.450 \\
Test 2 & 0.524 & 0.054 & 0.497 & 0.551 & 0.244 & 0.637 \\
Test 3 & 0.835 & 0.051 & 0.810 & 0.861 & 0.488 & 0.894 \\
Test 4 & 0.947 & 0.043 & 0.925 & 0.968 & 0.563 & 0.990 \\
\hline
\end{tabular}


less than or equal to 1 . The range obtained for the correlation coefficient specifies the type of the relation, which is expressed as follows:

correlation coefficient $=$

$$
\left\{\begin{array}{l}
r<0.2 \quad \text { linear relation is extremely weak, } \\
0.2 \leq r<0.4 \quad \text { linear relation is weak, } \\
0.4 \leq r<0.6 \quad \text { linear relation is moderate, } \\
0.6 \leq r<0.8 \quad \text { linear relation is strong, } \\
r>0.8 \quad \text { linear relation is extremely strong. }
\end{array}\right.
$$

Accordingly, correlations are equal to 1 or -1 . In order to analyze the cascading effects better, the main stations on the route are examined. Correlation coefficients of the train delay at different stations are obtained in Table 9.

It can be observed from this table that the correlation coefficients are greater than 0.8 , which means that there is an extremely strong linear correlation between delays at an individual station and delays at the following stations. The correlation of delays between the major stations is plotted in Figure 13. As observed, the cascading effect of the delay is diminished gradually at the end of the route. In addition, it is found that the correlation is stronger when the arrival/departure delays are closer, especially at the same station. The results show that the correlation coefficient is larger for the stations that are close to each other. Garmsar, Semnan, and Shahrood Stations are the main ones along the route. In particular, Shahrood Station is a traffic control center and manages traffic flow in several neighboring station controls. The train

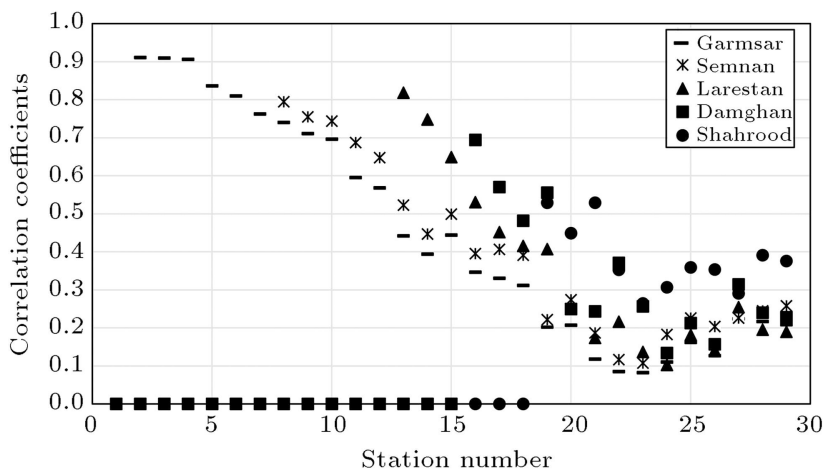

Figure 13. The correlation between delays between the major stations.

delays at Garmsar and Semnan Stations are gradual with the highest correlation (over 0.75 to 0.80 ). After Semnan Station (the main station on the route), the delay correlation is reduced greatly. The results show that the main station on the route (Semnan Station) as well as the traffic control centers have been able to manage the train delays properly.

\subsection{Capacity consumption analysis using UIC406 method}

A simple, useful and fast method to appraise the capacity consumption of rail routes is proposed, called UIC406 method [37]. The method of the UIC406 booklet is applicable to both single- and double-track blocks. This method is based on the railway route and timetable. According to this method, a railway is broken into smaller segments such as blocks based on data of train movement graph; then, the train movement graph is compressed and capacity of every

Table 9. Correlation coefficients of the train delay at different stations.

\begin{tabular}{|c|c|c|c|c|c|c|c|c|c|c|c|c|c|}
\hline Stations & 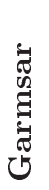 & 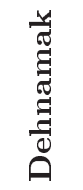 & $\begin{array}{l}0 \\
\stackrel{0}{\circ} \\
\stackrel{\sigma}{\oplus}\end{array}$ & 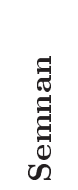 & 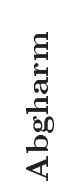 & 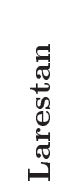 & 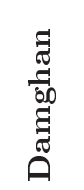 & 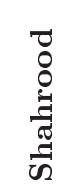 & 苟 & 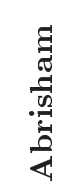 & 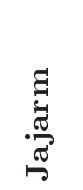 & 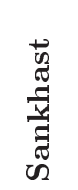 & $\begin{array}{l}\frac{0}{\pi} \\
\frac{1}{80} \\
\mathcal{D}^{\circ}\end{array}$ \\
\hline Garmsar & - & 0.91 & 0.84 & 0.76 & 0.71 & 0.57 & 0.44 & 0.31 & 0.08 & 0.11 & 0.16 & 0.22 & 0.21 \\
\hline Dehnamak & - & - & 0.86 & 0.8 & 0.73 & 0.57 & 0.44 & 0.32 & 0.1 & 0.15 & 0.19 & 0.24 & 0.23 \\
\hline Lahore & - & - & - & 0.84 & 0.79 & 0.6 & 0.46 & 0.34 & 0.09 & 0.16 & 0.18 & 0.22 & 0.21 \\
\hline Semnan & - & - & - & - & 0.75 & 0.65 & 0.5 & 0.39 & 0.12 & 0.18 & 0.23 & 0.23 & 0.26 \\
\hline Abgharm & - & - & - & - & - & 0.65 & 0.51 & 0.38 & 0.09 & 0.18 & 0.19 & 0.2 & 0.22 \\
\hline Larestan & - & - & - & - & - & - & 0.65 & 0.42 & 0.22 & 0.1 & 0.18 & 0.25 & 0.19 \\
\hline Damghan & - & - & - & - & - & - & - & 0.48 & 0.37 & 0.13 & 0.21 & 0.31 & 0.23 \\
\hline Shahrood & - & - & - & - & - & - & - & - & 0.35 & 0.31 & 0.36 & 0.29 & 0.38 \\
\hline Bkran & - & - & - & - & - & - & - & - & - & 0.36 & 0.48 & 0.48 & 0.41 \\
\hline Abrisham & - & - & - & - & - & - & - & - & - & - & 0.62 & 0.34 & 0.41 \\
\hline Jajarm & - & - & - & - & - & - & - & - & - & - & - & 0.51 & 0.6 \\
\hline Sankhast & - & - & - & - & - & - & - & - & - & - & - & - & 0.57 \\
\hline Neghab & - & - & - & - & - & - & - & - & - & - & - & - & - \\
\hline
\end{tabular}


small segment is calculated; finally, route's capacity consumption will be calculated. The capacity consumption of the planned timetables can be exhibited virtually by approximation of stairway of impasse times as much as possible; however, this is done irrespective of buffer times and without altering trains' order and is called compression method. In compression method, the following actions are performed to analyze the planned timetable:

1. Identification of buffer times in the traffic graph;

2. Finding the critical buffer chain, e.g., a route in the graph with the least total of buffer times;

3. Calculation of route occupancy in every time window of the critical segments.

In UIC406 method, the capacity consumption is calculated using total infrastructure occupancy times, buffer times, and supplementary times according to Eqs. (10) and (11):

$$
\begin{aligned}
& k=A+B+C+D, \\
& K=\frac{k}{U} \times 100,
\end{aligned}
$$

where $k$ is the total consumption time (min), $A$ denotes the infrastructure occupancy $(\mathrm{min}), B$ represents the buffer time ( $\mathrm{min}), C$ indicates the supplement for single-track lines $(\min ), D$ stands for supplements for maintenance $(\min ), K$ is the capacity consumption rate (\%), and $U$ represents the chosen time window (min). Capacity consumption of a route varies according to the reference time which can be a day, a week, or a season. If the route is closed during some hours due to maintenance operations, the maintenance time would be subtracted from 1440 minutes. In order to assess the capacity of a route, an analysis shall be carried out for every single block along the route. The highest capacity consumption value on any section of the route shall determine the capacity consumption of the route. Capacity and bottlenecks for a route are assessed according to UIC406 booklet recommendations, shown in Table 10. This table demonstrates the critical capacity consumption rates based on crossing traffic type including dedicated suburban passenger traffic, dedicated high-speed lines, and passenger-freight mixed-traffic lines and the time window, which can be peak hour or daily period.

As an example, the maximum acceptable capacity consumption rate in a daily time window for mixedtraffic lines is equal to $60 \%$. With the aim of maintaining the quality of service, railway's capacity consumption shall not exceed the corresponding values in Table 10. This means that the average buffer time between two trains should not be less than the average time headway of the line. However, it is still possible to impose greater capacity consumption rates on single- and double-track routes with long distances among their stations and small differences between train speeds, respectively [38]. In case that the capacity consumption of a route or a block is equal to or greater than the presented values of Table 10, the route or block may be recognized as a bottleneck, and a mechanism to increase its capacity should be considered.

\subsubsection{Occupancy rate analysis using UIC406}

The capacity of a route can be expressed in the form of a delay chart. This chart shows the average delays of every train as a function of a number of trains (in the unit of time). Delay time is one of the main operation quality measurements. Through the instrumentality of a delay chart, it is possible to suggest a proposed range for the route's capacity. Through simulations of numerous European railways, it is perceived that the minimum relative sensitivity of delays is obtainable from a traffic flow in the range of 50 to 60 percent of route's physical capacity [38]. In Figure 14, the chart of average travelling times versus a number of trains is exhibited in order to demonstrate an analytical tool

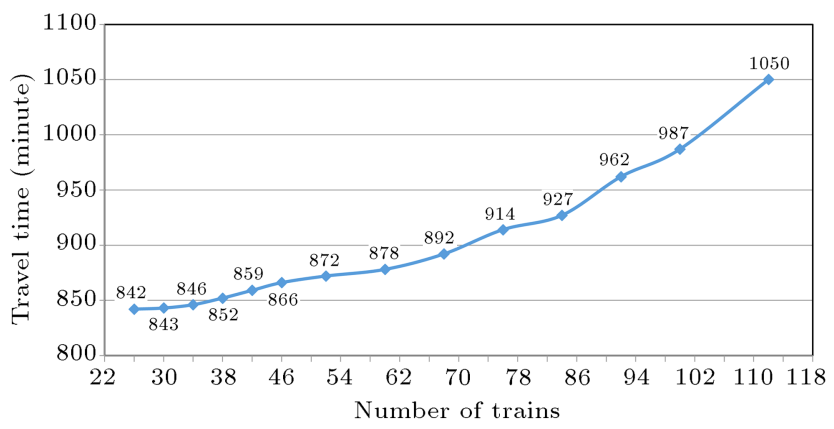

Figure 14. Dispatching number versus travelling times.

Table 10. Recommended capacity consumption constraints (UIC Leaflet 406, 2004).

\begin{tabular}{ccc}
\hline \multirow{2}{*}{ Type of line } & \multicolumn{2}{c}{$\begin{array}{c}\text { Maximum capacity } \\
\text { consumption rate in }\end{array}$} \\
\cline { 2 - 3 } & Peak hour & Daily period \\
\hline Dedicated suburban passenger traffic & $85 \%$ & $70 \%$ \\
Dedicated high-speed line & $75 \%$ & $60 \%$ \\
Mixed-traffic lines & $75 \%$ & $60 \%$ \\
\hline
\end{tabular}


to evaluate route's physical capacity. Train movement simulation is repeated 10 times for the summer period. It can be observed from the figure that travelling times of trains increase as trains increase in number. The main cause of this increment in trains' travelling times is due to the growth of meet/pass times caused by the raised number of trains. The least number of trains that leads to the sharper grow of trains' travelling time and is about 90 trains in this case.

In order to investigate the relationship between routes' occupancy rate and the delays, various conditions are examined. Tehran-Mashhad railway route is analyzed using simulation outcomes and based on UIC406 method. A number of trains are also examined, starting from 26 trains per day by steps of 4 trains until reaching 114 trains per day. Trains' dwelling times (average value of every train on every trip), scheduled dwelling times (average value of every train on every trip), and total stopping times caused by meet/pass and accidental happenings (average value of every train on every trip) are calculated separately for inbound and outbound trip directions. In Table 11, the capacity consumptions are calculated for all blocks of the route. In accordance with the proposed methodology, railway route is broken into blocks and capacity of every block is calculated day by day. The whole route's capacity consumption is equal to the block's with the highest capacity consumption, and the mentioned block is considered as the critical block. In every examination, capacity consumption is also calculated for each of inbound and outbound trips. In this regard, train movement graphs are compressed and, on this basis, occupancy rate of blocks is calculated. Therefore, capacity consumption in every scenario is equal to the value in the last row of Table 11. For instance, in the case of dispatching 60 trains per day, the occupancy rate of blocks is equal to $53.7 \%$ in inbound and $58.9 \%$ in outbound directions, respectively.

In Figures 15 and 16, the occupancy rate' variation trends in the route are illustrated respectively for inbound and outbound directions. The relationship between total delays and route's occupancy rate is illustrated in Figure 17. Occupancy rate in the inbound direction increases from 23.3 to $89.9 \%$ and, in reverse direction, rises from $25.5 \%$ to $98.1 \%$. By enlarging the number of trains, capacity consumption percentage grows. Based on the results obtained from calculations and proposed recommendations for capacity consumption in Table 11, the double-track route of TehranMashhad in the scenarios with 68 to 100 operating trains has critical blocks (colored cells in Table 11). These critical blocks are the bottlenecks of this route because their capacity consumption is more than $60 \%$. Therefore, dispatching more than 60 trains in this route would lead to a reduction of its performance and operational desirability.

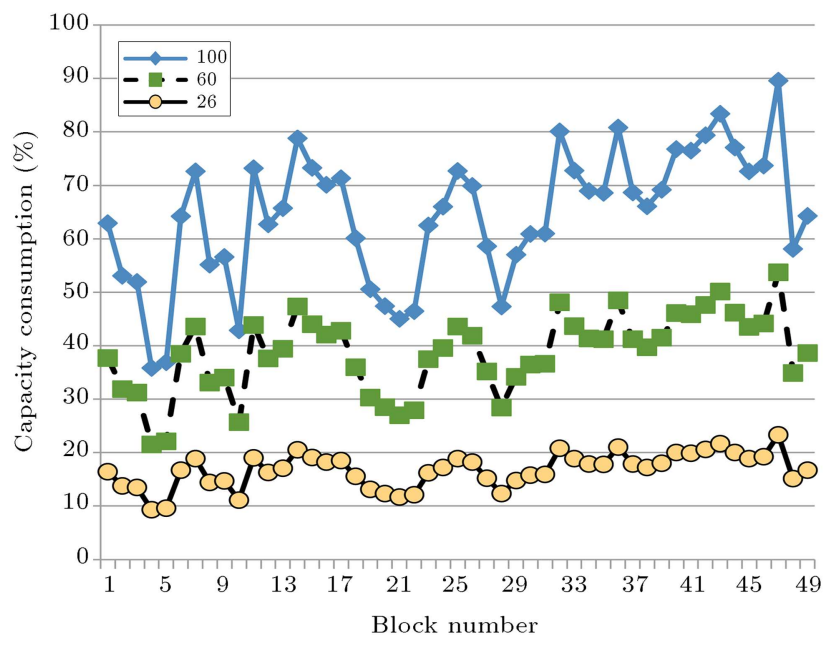

Figure 15. Capacity consumption in eastbound railway line.

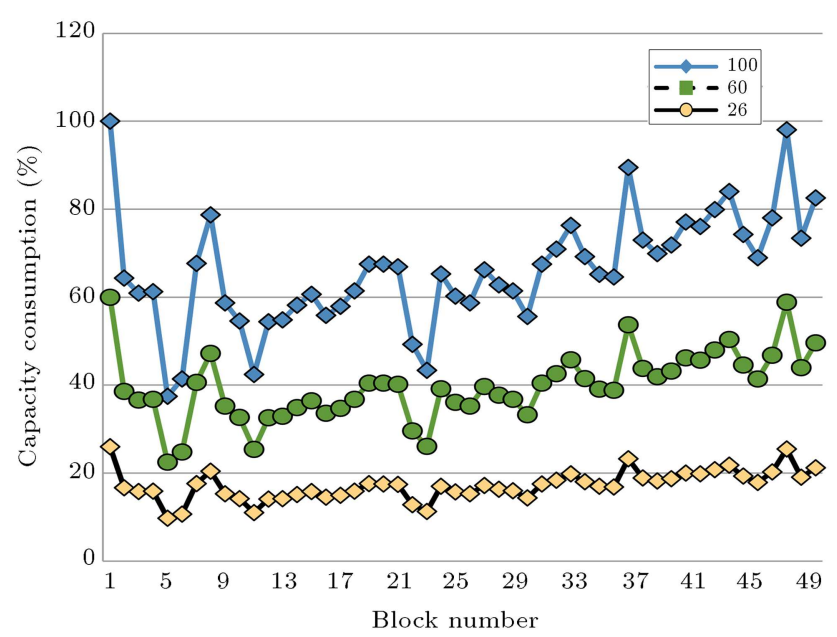

Figure 16. Capacity consumption in westbound railway line.

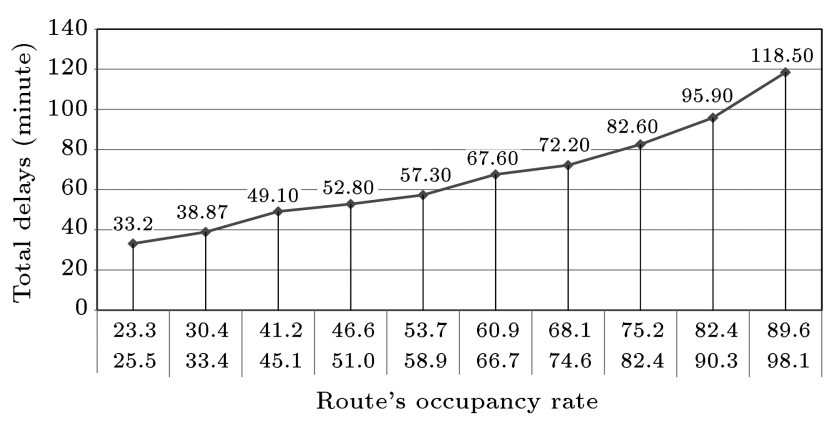

Figure 17. Relationship between total delays and route's occupancy rate.

\section{Conclusion}

Reliability is one of the most important measures of performance in railway systems. The previous studies were limited to operational stability of rail transportation systems, and there is a lack of sufficient research on the effect of the electrification and 
Table 11. Capacity consumption of Tehran-Mashhad route.

\begin{tabular}{|c|c|c|c|c|c|c|c|c|c|c|c|c|c|c|c|c|c|c|c|c|}
\hline \multirow{2}{*}{ Block } & \multicolumn{10}{|c|}{ Number of dispatched trains in outbound direction } & \multicolumn{10}{|c|}{ Number of dispatched trains in inbound direction } \\
\hline & 26 & 34 & 46 & 52 & 60 & 68 & 76 & 84 & 92 & 100 & 26 & 34 & 46 & 52 & 60 & 68 & 76 & 94 & 92 & 100 \\
\hline 1 & 16.7 & 21.8 & 29.6 & 33.4 & 38.6 & 43.7 & 48.8 & 54.0 & 59.1 & 64.3 & 16.4 & 21.4 & 28.9 & 32.7 & 37.7 & 42.8 & 47.8 & 52.8 & 57.9 & 62.9 \\
\hline 2 & 15.8 & 20.7 & 28.0 & 31.7 & 36.6 & 41.4 & 46.3 & 51.2 & 56.1 & 60.9 & 13.8 & 18.1 & 24.4 & 27.6 & 31.9 & 36.1 & 40.4 & 44.6 & 48.9 & 53.1 \\
\hline 3 & 15.9 & 20.8 & 28.2 & 31.9 & 36.8 & 41.7 & 46.6 & 51.5 & 56.4 & 61.3 & 13.5 & 17.7 & 23.9 & 27.0 & 31.2 & 35.3 & 39.5 & 43.6 & 47.8 & 51.9 \\
\hline 4 & 9.7 & 12.7 & 17.2 & 19.5 & 22.5 & 25.5 & 28.5 & 31.5 & 34.5 & 37.5 & 9.3 & 12.2 & 16.5 & 18.6 & 21.5 & 24.3 & 27.2 & 30.1 & 32.9 & 35.8 \\
\hline 5 & 10.7 & 14.9 & 19.0 & 21.5 & 24.8 & 28.2 & 31.5 & 34.8 & 38.1 & 41.4 & 9.6 & 12.5 & 17.0 & 19.2 & 22.1 & 25.1 & 28.0 & 31.0 & 33.9 & 36.9 \\
\hline 6 & 17.6 & 23.0 & 31.1 & 35.2 & 40.6 & 46.0 & 51.4 & 56.9 & 62.3 & 67.7 & 16.7 & 21.8 & 29.5 & 33.4 & 38.5 & 43.7 & 48.8 & 54.0 & 59.1 & 64.2 \\
\hline 7 & 20.4 & 26.8 & 36.2 & 40.9 & 47.2 & 53.5 & 59.8 & 66.1 & 72.4 & 78.7 & 18.9 & 24.7 & 33.4 & 37.8 & 43.6 & 49.4 & 55.2 & 61 & 66.8 & 72.6 \\
\hline 8 & 15.3 & 19.9 & 27.0 & 30.5 & 35.2 & 39.9 & 44.6 & 49.3 & 54.0 & 58.7 & 14.4 & 18.8 & 25.4 & 28.7 & 33.1 & 37.6 & 42.0 & 46.4 & 50.8 & 55.2 \\
\hline 9 & 14.2 & 18.6 & 25.1 & 28.4 & 32.7 & 37.1 & 41.5 & 45.8 & 50.2 & 54.6 & 14.7 & 19.2 & 26.0 & 29.4 & 34.0 & 38.5 & 43.0 & 47.6 & 52.1 & 56.6 \\
\hline 10 & 11.0 & 14.4 & 19.5 & 22.0 & 25.4 & 28.8 & 32.2 & 35.6 & 39.0 & 42.4 & 11.1 & 14.6 & 19.7 & 22.3 & 25.7 & 29.2 & 32.6 & 36.0 & 39.4 & 42.9 \\
\hline 11 & 14.1 & 18.5 & 25.0 & 28.3 & 32.6 & 37.0 & 41.4 & 45.7 & 50.1 & 54.4 & 19.0 & 24.9 & 33.6 & 38.0 & 43.9 & 49.7 & 55.6 & 61.4 & 67.3 & 73.2 \\
\hline 12 & 14.2 & 18.6 & 25.2 & 28.5 & 32.9 & 37.2 & 41.6 & 46.0 & 50.4 & 54.8 & 16.3 & 21.3 & 28.9 & 32.6 & 37.6 & 42.7 & 47.7 & 52.7 & 57.7 & 62.7 \\
\hline 13 & 15.1 & 19.8 & 26.8 & 30.3 & 34.9 & 39.6 & 44.2 & 48.9 & 53.5 & 58.2 & 17.1 & 22.3 & 30.2 & 34.2 & 39.4 & 44.7 & 49.9 & 55.2 & 60.4 & 65.7 \\
\hline 14 & 15.8 & 20.6 & 27.9 & 31.5 & 36.4 & 41.2 & 46.1 & 50.9 & 55.8 & 60.7 & 20.5 & 26.8 & 36.2 & 41.0 & 47.3 & 53.6 & 59.9 & 66.2 & 72.5 & 78.8 \\
\hline 15 & 14.5 & 19.0 & 25.7 & 29.1 & 33.6 & 38.0 & 42.5 & 47.0 & 51.5 & 55.9 & 19.1 & 24.9 & 33.7 & 38.1 & 44.0 & 49.8 & 55.7 & 61.6 & 67.4 & 73.3 \\
\hline 16 & 15.0 & 19.7 & 26.6 & 30.1 & 34.7 & 39.3 & 44.0 & 48.6 & 53.2 & 57.9 & 18.2 & 23.8 & 32.2 & 36.4 & 42.1 & 47.7 & 53.3 & 58.9 & 64.5 & 70.1 \\
\hline 17 & 15.9 & 20.9 & 28.2 & 31.9 & 36.8 & 41.7 & 46.7 & 51.6 & 56.5 & 61.4 & 18.5 & 24.3 & 32.8 & 37.1 & 42.8 & 48.5 & 54.2 & 59.9 & 65.6 & 71.3 \\
\hline 18 & 17.6 & 22.9 & 31.1 & 35.1 & 40.5 & 45.9 & 51.3 & 56.7 & 62.1 & 67.5 & 15.6 & 20.4 & 27.6 & 31.2 & 36.0 & 40.8 & 45.6 & 50.4 & 55.2 & 60.1 \\
\hline 19 & 17.5 & 22.9 & 31.0 & 35.1 & 40.5 & 45.9 & 51.3 & 56.7 & 62.1 & 67.5 & 13.1 & 17.2 & 23.3 & 26.3 & 30.3 & 34.4 & 38.4 & 42.5 & 46.5 & 50.6 \\
\hline 20 & 17.4 & 22.8 & 30.8 & 34.8 & 40.2 & 45.5 & 50.9 & 56.2 & 61.6 & 66.9 & 12.3 & 16.1 & 21.8 & 24.7 & 28.5 & 32.3 & 36.0 & 39.8 & 43.6 & 47.4 \\
\hline 21 & 12.8 & 16.8 & 22.7 & 25.6 & 29.6 & 33.5 & 37.5 & 41.4 & 45.4 & 49.3 & 11.7 & 15.3 & 20.7 & 23.4 & 27.0 & 30.6 & 34.2 & 37.8 & 41.4 & 45.0 \\
\hline 22 & 11.3 & 14.8 & 20.0 & 22.6 & 26.1 & 29.5 & 33.0 & 36.5 & 40.0 & 43.4 & 12.1 & 15.8 & 21.4 & 24.2 & 27.9 & 31.6 & 35.3 & 39.1 & 42.8 & 46.5 \\
\hline 23 & 17.0 & 22.2 & 30.0 & 33.9 & 39.2 & 44.4 & 49.6 & 54.8 & 60.1 & 65.3 & 16.2 & 21.2 & 28.7 & 32.5 & 37.5 & 42.5 & 47.5 & 52.5 & 57.5 & 62.5 \\
\hline 24 & 15.7 & 20.5 & 27.7 & 31.3 & 36.1 & 41.0 & 45.8 & 50.6 & 55.4 & 60.2 & 17.2 & 22.4 & 30.3 & 34.3 & 39.6 & 44.9 & 50.1 & 55.4 & 60.7 & 66 \\
\hline 25 & 15.3 & 20.0 & 27.0 & 30.5 & 35.2 & 39.9 & 44.6 & 49.3 & 54.0 & 58.7 & 18.9 & 24.7 & 33.4 & 37.8 & 43.6 & 49.4 & 55.3 & 61.1 & 66.9 & 72.7 \\
\hline 26 & 17.2 & 22.5 & 30.4 & 34.4 & 39.7 & 45.0 & 50.3 & 55.6 & 60.9 & 66.2 & 18.2 & 23.8 & 32.2 & 36.3 & 41.9 & 47.5 & 53.1 & 58.7 & 64.3 & 69.9 \\
\hline 27 & 16.3 & 21.3 & 28.9 & 32.6 & 37.7 & 42.7 & 47.7 & 52.7 & 57.7 & 62.8 & 15.2 & 19.9 & 27.0 & 30.5 & 35.2 & 39.9 & 44.6 & 49.3 & 53.9 & 58.6 \\
\hline 28 & 16.0 & 20.9 & 28.2 & 31.9 & 36.8 & 41.7 & 46.6 & 51.5 & 56.4 & 61.4 & 12.3 & 16.1 & 21.8 & 24.6 & 28.4 & 32.2 & 36.0 & 39.8 & 43.6 & 47.3 \\
\hline 29 & 14.4 & 18.9 & 25.6 & 28.9 & 33.3 & 37.8 & 42.2 & 46.7 & 51.1 & 55.6 & 14.8 & 19.4 & 26.2 & 29.6 & 34.2 & 38.7 & 43.3 & 47.8 & 52.4 & 57.0 \\
\hline 30 & 17.5 & 22.9 & 31.0 & 35.1 & 40.5 & 45.9 & 51.3 & 56.7 & 62.1 & 67.5 & 15.8 & 20.7 & 28.0 & 31.6 & 36.5 & 41.4 & 46.2 & 51.1 & 56.0 & 60.9 \\
\hline 31 & 18.4 & 24.1 & 32.6 & 36.9 & 42.6 & 48.2 & 53.9 & 59.6 & 65.3 & 70.9 & 15.9 & 20.7 & 28.1 & 31.7 & 36.6 & 41.5 & 46.4 & 51.3 & 56.1 & 61.0 \\
\hline 32 & 19.8 & 25.9 & 35.1 & 39.7 & 45.8 & 51.9 & 58.0 & 64.1 & 70.2 & 76.3 & 20.8 & 27.2 & 36.9 & 41.7 & 48.1 & 54.5 & 60.9 & 67.3 & 73.7 & 80.1 \\
\hline 33 & 18.0 & 23.5 & 31.8 & 36.0 & 41.5 & 47.1 & 52.6 & 58.1 & 63.7 & 69.2 & 18.9 & 24.7 & 33.5 & 37.9 & 43.7 & 49.5 & 55.3 & 61.1 & 67 & 72.8 \\
\hline 34 & 17.0 & 22.2 & 30.0 & 33.9 & 39.1 & 44.3 & 49.6 & 54.8 & 60.0 & 65.2 & 17.9 & 23.5 & 31.7 & 35.9 & 41.4 & 46.9 & 52.4 & 58.0 & 63.5 & 69.0 \\
\hline 35 & 16.8 & 22.0 & 29.7 & 33.6 & 38.8 & 43.9 & 49.1 & 54.3 & 59.4 & 64.6 & 17.8 & 23.3 & 31.6 & 35.7 & 41.2 & 46.7 & 52.2 & 57.6 & 63.1 & 68.6 \\
\hline 36 & 23.3 & 30.4 & 41.2 & 46.5 & 53.7 & 60.9 & 68 & 75.2 & 82.3 & 89.5 & 21.0 & 27.5 & 37.2 & 42.0 & 48.5 & 54.9 & 61.4 & 67.8 & 74.3 & 80.8 \\
\hline 37 & 18.9 & 24.8 & 33.6 & 37.9 & 43.8 & 49.6 & 55.5 & 61.3 & 67.1 & 73.0 & 17.9 & 23.4 & 31.6 & 35.7 & 41.2 & 46.7 & 52.2 & 57.7 & 63.2 & 68.7 \\
\hline 38 & 18.2 & 23.8 & 32.1 & 36.3 & 41.9 & 47.5 & 53.1 & 58.7 & 64.3 & 69.9 & 17.2 & 22.5 & 30.4 & 34.4 & 39.7 & 45.0 & 50.3 & 55.6 & 60.8 & 66.1 \\
\hline 39 & 18.7 & 24.5 & 33.1 & 37.4 & 43.2 & 48.9 & 54.7 & 60.4 & 66.2 & 71.9 & 18.0 & 23.5 & 31.8 & 36.0 & 41.5 & 47.1 & 52.6 & 58.2 & 63.7 & 69.2 \\
\hline 40 & 20.0 & 26.2 & 35.5 & 40.1 & 46.2 & 52.4 & 58.6 & 64.7 & 70.9 & 77.1 & 20.0 & 26.1 & 35.3 & 40.0 & 46.1 & 52.3 & 58.4 & 64.5 & 70.7 & 76.8 \\
\hline 41 & 19.8 & 25.9 & 35.0 & 39.6 & 45.7 & 51.8 & 57.9 & 64.0 & 70.0 & 76.1 & 19.9 & 26.0 & 35.2 & 39.8 & 45.9 & 52.0 & 58.2 & 64.3 & 70.4 & 76.5 \\
\hline 42 & 20.8 & 27.2 & 36.8 & 41.6 & 48.0 & 54.3 & 60.7 & 67.1 & 73.5 & 79.9 & 20.6 & 27.0 & 36.5 & 41.3 & 47.6 & 54.0 & 60.3 & 66.7 & 73.1 & 79.4 \\
\hline 43 & 21.8 & 28.6 & 38.7 & 43.7 & 50.4 & 57.2 & 63.9 & 70.6 & 77.3 & 84.0 & 21.7 & 28.4 & 38.4 & 43.4 & 50.1 & 56.7 & 63.4 & 70.1 & 76.8 & 83.4 \\
\hline 44 & 19.3 & 25.3 & 34.2 & 38.6 & 44.6 & 50.5 & 56.4 & 62.4 & 68.3 & 74.3 & 20.0 & 26.2 & 35.4 & 40.1 & 46.2 & 52.4 & 58.6 & 64.7 & 70.9 & 77.1 \\
\hline 45 & 17.9 & 23.5 & 31.7 & 35.9 & 41.4 & 46.9 & 52.4 & 57.9 & 63.5 & 69.0 & 18.9 & 24.7 & 33.4 & 37.7 & 43.5 & 49.3 & 55.1 & 61.0 & 66.8 & 72.6 \\
\hline 46 & 20.3 & 26.5 & 35.9 & 40.5 & 46.8 & 53.0 & 59.3 & 65.5 & 71.7 & 78.0 & 19.2 & 25.1 & 33.9 & 38.3 & 44.2 & 50.1 & 56.0 & 61.9 & 67.8 & 73.7 \\
\hline 47 & 25.5 & 33.4 & 45.1 & 51.0 & 58.9 & 66.7 & 74.6 & 82.4 & 90.3 & 98.1 & 23.3 & 30.4 & 41.2 & 46.6 & 53.7 & 60.9 & 68.1 & 75.2 & 82.4 & 89.6 \\
\hline 48 & 19.1 & 24.9 & 33.7 & 38.1 & 44.0 & 49.9 & 55.7 & 61.6 & 67.5 & 73.4 & 15.1 & 19.8 & 26.7 & 30.2 & 34.9 & 39.5 & 44.2 & 48.8 & 53.5 & 58.1 \\
\hline 49 & 21.2 & 28.1 & 38.0 & 42.9 & 49.6 & 56.2 & 62.8 & 69.4 & 76.0 & 82.6 & 16.7 & 21.9 & 29.6 & 33.4 & 38.6 & 43.7 & 48.9 & 54.0 & 59.2 & 64.3 \\
\hline $\begin{array}{c}\text { Occupancy } \\
\text { rate }\end{array}$ & 25.5 & 33.4 & 45.1 & 51.0 & $\underline{58.9}$ & 66.7 & 74.6 & 82.4 & 90.3 & 98.1 & 23.3 & 30.4 & 41.2 & 46.6 & $\underline{53.7}$ & 60.9 & 68.1 & 75.2 & 82.4 & 89.6 \\
\hline
\end{tabular}

infrastructure development on the reliability of the rail system. The present research was conducted to find the extent of factors that affects the reliability of train's services. Therefore, the effects of the doubling and electrification on reliability were studied. A simulation system was implemented to assess the reliability of the train's movements. The developed simulation model considered details of train operation and random disturbances. The simulation model used the historical data of train movements such as probability distribu- 
tion of the running time in block sections, dwelling at the station, and infrastructure failures.

In this paper, the reliability of the train service was calculated as the percentage of the number of trains arrived at the destination in the allowable delay range. Four various tests with random parameters were used to determine the trains movement reliability. In order to compare electrified and non-electrified cases, they have to be compared with similar conditions. For this purpose, train movement parameters of Tehran-Mashhad and Tabriz-Jolfa railways were used for non-electric and electric trains, respectively. The operational characteristics of the existing electrified route (Tabriz-Jolfa) were implemented on the TehranMashhad route. These tests were analyzed, and the results showed that doubling and electrification greatly improved the reliability. According to the experimental results of the present research, the double-track route leads to the elimination of crossing delay; on the other hand, electrification reduces the probability of infrastructure failure and causes fewer failures compared with the non-electrified case. The result justifies that the effect of doubling and electrification on the reliability of train services is significant. Furthermore, the relationship between occupancy rate of the railways and delays of trains was studied using UIC406 method. To model train movements, the technique of simulation in stochastic mode was implemented. In the simulation model, the details of train movements were applied on railways in a stochastic manner. To investigate the relationship between occupancy rate and delays of trains, different conditions were evaluated for the Tehran-Mashhad route. According to the calculations, delays increased severely by dispatching more than 90 trains in the route. The main cause of this increment in average travelling times was due to the rise in the meet/pass times caused by dispatching excess number of trains in the route. Moreover, delays reached nearly 2 hours at $80 \%$ of route's occupancy. Occupancy rate in the direction increased from 23.3 to 89.9 percent and rose from 25.5 to 98.1 percent in the reverse direction. In this regard, the proposed model succeeded to provide the ability of choosing the desired operational condition considering a suitable delay time and performance cost. Therefore, the proposed model can be considered as a suitable tool to analyze and evaluate the performance of the Iranian railways.

As accounted for the future research, many of the modeling characteristics can be adapted to situations that are more realistic. One important extension of the current study is to consider the network case. In addition, it is worth mentioning that the simulation model can be extended to analyze other performance measures such as punctuality and robustness. Apart from the above-mentioned research directions, the authors aim to find the causes, e.g., different distances between adjacent stations or different train specifications, which lead to a different pattern for delay correlation along the route. This valuable information can be used to assess the reliability of the service or identify a possible action to control the cascading effects of the delays along the route.

\section{References}

1. Isaai, M.T. "An intelligent search technique for solving train scheduling problems: Simulated annealing and constraint satisfaction", Scientia Iranica, 14(5), pp. 442-449 (2007).

2. Cheng, Y.-H. and Y.-C. Tsai "Train delay and perceived-wait time: passengers' perspective", Transport Reviews, 34(6), pp. 710-729 (2014).

3. Hassannayebi, E., Zegordi, S.H., and Yaghini, M. "Train timetabling for an urban rail transit line using a Lagrangian relaxation approach", Applied Mathematical Modelling, 40(23-24), pp. 9892-9913 (2016).

4. Larsen, R., Pranzo, M., D'Ariano, A., Corman, F., and Pacciarelli, D. "Susceptibility of optimal train schedules to stochastic disturbances of process times", Flexible Services and Manufacturing Journal, 26(4) pp. 466-489 (2014).

5. Rausand, M. and Høyland, A. "System reliability theory: models, statistical methods, and applications", 396 John Wiley \& Sons (2004).

6. Hassannayebi, E., Zegordi, S.H., Amin-Naseri, M.R., and Yaghini, M. "Train timetabling at rapid rail transit lines: a robust multi-objective stochastic programming approach", Operational Research, 17(2), pp. 435-477 (2017).

7. Abril, M., Barber, F., Ingolotti, L., Salido, M.A., Tormos, P., and Lova, A. "An assessment of railway capacity", Transportation Research Part E: Logistics and Transportation Review, 44(5) pp. 774-806 (2008).

8. Corman, F., D'Ariano, A., Pacciarelli, D., and Pranzo, M. "Dispatching and coordination in multi-area railway traffic management", Computers \& Operations Research, 44 pp. 146-160 (2014).

9. Hassannayebi, E. and Zegordi, S.H. "Variable and adaptive neighbourhood search algorithms for rail rapid transit timetabling problem", Computers \& Operations Research, 78 pp. 439-453 (2017).

10. Morant, A., Gustafson, A., Söderholm, P., LarssonKr/aaik, P.O. and Kumar, U. "Safety and availability evaluation of railway operation based on the state of signalling systems", Proceedings of the Institution of Mechanical Engineers, Part F: Journal of Rail and Rapid Transit, pp. 0954409715624466 (2016).

11. Fayez, M.S., Kaylani, A., Cope, D., Rychlik, N., and Mollaghasemi, M. "Managing airport operations using simulation", Journal of Simulation, 2(1) pp. 41-52 (2008).

12. Kelton, W.D., Sadowski, R.P., and Sadowski, D.A. "Simulation with ARENA": McGraw-Hill, Inc. (2002). 
13. Sajedinejad, A., Mardani, S., Hasannayebi, E., and Kabirian, A. "SIMARAIL: simulation based optimization software for scheduling railway network", Proceedings of the Winter Simulation Conference (WSC), IEEE (2011).

14. Hasannayebi, E., Sajedinejad, A., Mardani, S., and Mohammadi K.S. "An integrated simulation model and evolutionary algorithm for train timetabling problem with considering train stops for praying", Proceedings of Simulation Conference (WSC), IEEE (2012).

15. Hassannayebi, E., Sajedinejad, A., and Mardani, S. "Urban rail transit planning using a two-stage simulation-based optimization approach", Simulation Modelling Practice and Theory, 49, pp. 151-166 (2014).

16. Jovanović, P., Kecman, P., Bojović, N., and Mandić, D. "Optimal allocation of buffer times to increase train schedule robustness", European Journal of Operational Research, 256(1) pp. 44-54 (2017).

17. Hassannayebi, E., Zegordi, S.H., Yaghini, M., and Amin-Naseri, M.R. "Timetable optimization models and methods for minimizing passenger waiting time at public transit terminals", Transportation Planning and Technology, 40(3), pp. 278-304 (2017).

18. Yaghini, M., Khoshraftar, M.M., and Seyedabadi, M. "Railway passenger train delay prediction via neural network model", Journal of advanced transportation, 47(3), pp. 355-368 (2013).

19. Hassannayebi, E. and Kiaynfar, F. "A greedy randomized adaptive search procedure to solve the train sequencing and stop scheduling problem in double track railway lines", Journal of Transportation Research, 9(3), pp. 235-257 (2012).

20. Vromans, M.J., Dekker, R., and Kroon, L.G. "Reliability and heterogeneity of railway services", European Journal of Operational Research, 172(2), pp. 647-665 (2006).

21. Rietveld, P., Bruinsma, F.R., and Van Vuuren, D.J. "Coping with unreliability in public transport chains: A case study for Netherlands", Transportation Research Part A: Policy and Practice, 35(6), pp. 539-559 (2001).

22. Hassannayebi, E., Zegordi, S.H., Amin-Naseri, M.R., and Yaghini, M. "Demand-oriented timetable design for urban rail transit under stochastic demand", Journal of Industrial and Systems Engineering, 9(3), pp. 28-56 (2016).

23. Hallowell, S.F. and Harker, P.T. "Predicting ontime performance in scheduled railroad operations: methodology and application to train scheduling", Transportation Research Part A: Policy and Practice, 32(4), pp. 279-295 (1998).

24. Huisman, T. and Boucherie, R.J. "Running times on railway sections with heterogeneous train traffic", Transportation Research Part B: Methodological, 35(3), pp. 271-292 (2001).

25. Carey, M. and Carville, S. "Scheduling and platforming trains at busy complex stations", Transportation
Research Part A: Policy and Practice, 37(3), pp. 195224 (2003).

26. Yin, Y., Lam, W.H., and Miller, M.A. "A simulationbased reliability assessment approach for congested transit network", Journal of Advanced Transportation, 38(1), pp. 27-44 (2004).

27. Dingler, M., Lai, Y.-C., and Barkan, C. "Impact of train type heterogeneity on single-track railway capacity", Transportation Research Record: Journal of the Transportation Research Board, 2117, pp. 41-49 (2009).

28. Murali, P., Dessouky, M., Ordóñez, F., and Palmer, K. "A delay estimation technique for single and doubletrack railroads", Transportation Research Part E: Logistics and Transportation Review, 46(4), pp. 483-495 (2010).

29. Marinov, M. and Viegas, J. "A mesoscopic simulation modelling methodology for analyzing and evaluating freight train operations in a rail network", Simulation Modelling Practice and Theory, 19(1), pp. 516-539 (2011).

30. Zheng, Y., Zhang, X., Bin, X.U., and Linli, W.A.N.G. "Carrying capacity reliability of railway networks", Journal of Transportation Systems Engineering and Information Technology, 11(4), pp. 16-21 (2011).

31. Eskandari, H., Rahaee, M.A., Memarpour, M., Hasannayebi, E., and Malek, S.A. "Evaluation of different berthing scenarios in Shahid Rajaee container terminal using discrete-event simulation", in Proceedings of Simulation Conference: Simulation: Making Decisions in a Complex World, IEEE Press (2013).

32. Ilati, G., Sheikholeslami, A., and Hassannayebi, E. "A simulation-based optimization approach for integrated port resource allocation problem", PROMET-Traffic \& Transportation, 26(3), pp. 243-255 (2014).

33. Corman, F., D'Ariano, A. and Hansen, I.A. "Evaluating disturbance robustness of railway schedules", Journal of Intelligent Transportation Systems, 18(1), pp. 106-120 (2014).

34. Shakibayifar, M., Hassannayebi, E., Mirzahossein, H., and Shahabi, A. "An integrated train scheduling and infrastructure development model in railway networks", Scientia Iranica, 24(6), pp. 3409-3422 (2017).

35. Hassannayebi, E., Sajedinejad, A. and Mardani, S. "Disruption management in urban rail transit system: A simulation based optimization approach", in Handbook of Research on Emerging Innovations in Rail Transportation Engineering, IgI-Global, pp. 420-450 (2016).

36. Shakibayifar, M., Sheikholeslami, A., and Corman, F. "A simulation-based optimization approach to reschedule train traffic in uncertain conditions during disruptions", Scientia Iranica, 25(2), pp. 646-662 (2018).

37. Yaghini, M., Sarmadi, M., Nikoo, N., and Momeni, M. "Capacity consumption analysis using heuristic solution method for under construction railway routes", Networks and Spatial Economics, 14(3-4), pp. 317-333 (2014). 
38. Hansen, I.A. and Pachl, J. "Railway timetable \& traffic analysis", Modelling Simulation, 1, pp. 1-288 (2008).

\section{Biographies}

Masoud Shakibayifar is a $\mathrm{PhD}$ candidate at the Department of Transportation Engineering and Planning, School of Civil Engineering, Iran University of Science \& Technology (IUST), He is doing the PhD thesis entitled "Train Re-Scheduling model for Reducing Delay under Disturbances". This research focuses on designing simulation-optimization methods for train traffic rescheduling in railways systems. His research interests are railway electrification, railway scheduling and rescheduling, and optimization of transportation systems under uncertainty. He obtained BSc (19972001) and MSc (2004-2006) degrees in Civil Engineering in Sharif University of Technology. He managed more than 15 transportation-planning projects in Iranian Railway Company and the Ministry of Roads and Urban Development. Recently, he has managed a research project related to the design of railway traffic simulation software for Iranian Railway Company.

Abdorreza Sheikholeslami is an Associate Professor at the Department of Transportation Engineering and Planning, School of Civil Engineering, Iran University of Science \& Technology (IUST). He received his BSc and MSc degrees from IUST. He received his $\mathrm{PhD}$ degree in "Transportation Engineering and Planning" from Iran University of Science and Technology in 2006. His research interests are transportation planning, transportation economics, railway scheduling, disturbance management, mathematical models, and optimization techniques for designing transportation systems. He is elected as the top student in technical and engineering group in Iran at 2001. He has experience of more than 20 years in teaching at IUST. He has published more than 80 scientific papers in ISI journals and international conferences.

Francesco Corman is an Assistant Professor in Institute for Transport Planning and Systems, ETH Zurich, Switzerland. His research interest relates to optimization of transport networks under uncertainty, linked to the optimization and automation in supply chain networks and logistic systems, especially with interconnected systems and modes, mathematical models and optimization techniques for traffic control in railways systems, optimal coordination strategies, and equity issues in logistics: robustness, reliability, resilience of transport networks under stochastic phenomena; analytics, information and uncertainty dynamics; Apriori and online data collection, and assessment of quality of information. He has more than 25 highimpact articles in journals and book chapters and more than 100 scientific papers in journals or peer-reviewed international conferences; he has received numerous awards and nominations. He has been involved in organizing and chairing of the International Conference on Computational Logistics 2015, among others. He has been the General Chair of Problem-Solving Competition, Informs Railway Application Section 2015 and 2016. He is a Guest Editor of major transportation journals (TRC, TRE, Public Transport) and participates actively in TRB and Informs community. He is the initiator of much international research exchange and coordination networks.

Yousef Shafahi is a Full Professor in Sharif University of Technology, Department of Civil Engineering, 2014now. He is currently a Member of the Board of Air Transportation Scientific Society: 2009-now and the Head of Transportation Engineering \& Planning Division, Civil Engineering Department, Sharif University of Technology, 2014-now. He received his $\mathrm{PhD}$ in Civil Engineering, University of Maryland, College Park, MD, USA, 1997. His research interest relates to transport planning, e.g., urban transportation planning; road, rail, and air transportation; transit networks design and scheduling; Applications of Operation Research, Soft Computing, and Simulation in Transportation. He has conducted a comprehensive urban and suburban transportation planning project, e.g., a model for finding the threshold to electrify railroads of Iranian Railways. Objectives include designing a system to address some important management questions in the railway industry, such as (a) when should we start to electrify a railway system (b) how does variation of different relative weighting factors such as construction, operation, and maintenance costs, travelling time, and reliability affect the threshold of electrification. His teaching experiences include transportation engineering, transportation planning, systems simulation railway engineering airport planning and design, advanced engineering mathematics, operation research, statistics, probability theory, and mathematics. 